\title{
Tackling Energy Poverty through Collective Advisory Assemblies and Electricity and Comfort Monitoring Campaigns
}

\author{
Joana Ortiz ${ }^{1, *(\mathbb{C}, \text { Mariana Jiménez Martínez }}{ }^{2}$, Alba Alegría-Sala ${ }^{3}$, Sergio Tirado-Herrero ${ }^{4}$, \\ Irene González Pijuan ${ }^{5,6}\left(\mathbb{D}\right.$, Mònica Guiteras Blaya ${ }^{5}$ and Lluc Canals Casals ${ }^{2,3}$ (i)
}

1 Thermal Energy and Building Performance Group, Catalonia Institute for Energy Research (IREC), Jardins de les Dones de Negre 1, 2a, 08930 Sant Adrià de Besòs, Spain

2 Energy Systems Analytics Group, Catalonia Institute for Energy Research (IREC), Jardins de les Dones de Negre 1, 2a, 08930 Sant Adrià de Besòs, Spain; mcjimenez@irec.cat (M.J.M.); 1luc.canals@upc.edu (L.C.C.)

3 Project and Construction Engineering Department, Polytechnic University of Catalonia, Avda. Diagonal 647, 08028 Barcelona, Spain; alba.94ras@gmail.com

4 Institute of Environmental Science and Technology (ICTA), Universitat Autònoma de Barcelona (UAB), 08193 Cerdanyola del Vallès, Spain; Sergio.Tirado@uab.cat

5 Enginyeria Sense Fronteres, Carrer Múrcia 24 Baixos, 08027 Barcelona, Spain; irene.gonzalez@esf-cat.org (I.G.P.); monica.guiteras@esf-cat.org (M.G.B.)

6 Centre for Regional Economic Social Research, Sheffield Hallam University, Howard St., Sheffield City Centre, Sheffield S1 1WB, UK

* Correspondence: jortiz@irec.cat

\section{check for} updates

Citation: Ortiz, J.; Jiménez Martínez, M.; Alegría-Sala, A.; Tirado-Herrero,

S.; González Pijuan, I.; Guiteras Blaya,

M.; Canals Casals, L. Tackling Energy

Poverty through Collective Advisory Assemblies and Electricity and Comfort Monitoring Campaigns. Sustainability 2021, 13, 9671. https:// doi.org/10.3390/su13179671

Academic Editor:

Samuel Asumadu-Sarkodie

Received: 21 July 2021

Accepted: 24 August 2021

Published: 27 August 2021

Publisher's Note: MDPI stays neutral with regard to jurisdictional claims in published maps and institutional affiliations.

Copyright: (c) 2021 by the authors. Licensee MDPI, Basel, Switzerland. This article is an open access article distributed under the terms and conditions of the Creative Commons Attribution (CC BY) license (https:// creativecommons.org/licenses/by/ $4.0 /)$.
Abstract: The present work aims to describe and analyze the results of the interventions carried out in the Barcelona pilot site of the EmpowerMed project. The overall objective of EmpowerMed is to tackle energy poverty and to help improve the health of people in coastal areas of Mediterranean countries, with a particular focus on women. The main support approach implemented in Barcelona is Collective Advisory Assemblies (CAA), in the framework of Alliance against Energy Poverty. CAA is an innovative, collaborative empowering engagement tool that offers an alternative to the more traditional one-off individual household advice and support approaches. CAAs take place together with a monitoring campaign where: electricity consumption is analyzed to optimize the supply contracts, and indoor environmental comfort to provide recommendations for wellbeing improvement. Through the different approaches, a characterization of the people that have participated in the Barcelona pilot site was completed, from a socioeconomic, energy, thermal comfort and air quality perspective. Additionally, it was compared with a group of energy poverty non-affected households, which are involved in the monitoring campaign. Finally, the impact was quantified in terms of empowerment of energy poverty population and, potential economic savings.

Keywords: energy poverty; collective advisory assembly; smart meters; thermal comfort; air quality; gender

\section{Introduction}

While the European Union is spearheading global action on the climate emergency, millions of Europeans are unable to access a sufficient level of domestic energy services for fully participating in the lifestyles, customs and activities that define membership of society. This condition has become widely known as energy or fuel poverty (EP) in the scientific and policy literature and is defined as the "inability to attain a socially and materially necessitated level of domestic energy services" [1]. According to the European Energy Poverty Observatory (EPOV), tens of millions of Europeans suffer from high energy expenses, cold homes and arrears on utility bills among other symptoms [2]. Spatial differences in incidence rates signal Eastern and Southern Member States (including Spain) as a "periphery" of EU countries displaying EP rates significantly higher than those in 
the North-Western "core" of nations where just a small fraction of their populations are affected $[3,4]$.

Low incomes, increasing energy prices, and poor energy performance of buildings have been identified as key drivers for EP in the EU context [5-8] As EP is a multifaceted problem [9], studies identifying or characterizing EP-affected households from different perspectives are available for several European locations. These include socio-economic [10-13], energy consumption [12,13], energy expenses [10-13], thermal comfort [10,11], dwelling characteristics [10-13], physical health [14,15], mental health and social relations [16] and gender [15,17] dimensions. In order to provide a point of comparison, results from EP-affected households have been often compared against non-affected peers in previous research. This is the case of the statistical analysis carried out by Papada and Kaliampakos to measure EP levels in Greece [18].

Recently, the adoption of smart meters in some EU-member states has facilitated access to household energy consumption data to an unprecedented level of detail, promoting its usage in EP characterization studies, especially when electricity consumption is considered. Smart meter data are often complemented by quantitative or qualitative survey questions, and tend to include thermal comfort evaluations as they are not only related to energy usage but work as EP indicators themselves [19]. An example is the work by Gouveia et al. [12] that analyzed electricity consumption patterns and thermal comfort levels in 388 households from Évora, Portugal, using smart-meter data, survey responses and buildings energy use simulations, differentiating between EP-affected and non-affected consumers. Data retrieved from smart meters can also be used for the assessment of EP mitigation actions based on bill optimization, as Antepara et al. propose in their analysis of an intervention providing energy service advice to vulnerable households in the Basque Country [20]. To the best of our knowledge, no other research that combines smart meter, thermal comfort and indoor air quality measurement data to characterize EP has yet been carried out in the EU.

Within the Mediterranean basin, the Metropolitan Area of Barcelona (which includes the city of Barcelona) is home to more than 3.2 million people and the eighth-largest metropolitan region in Europe. Its Mediterranean climate of mild winters and hot summers make the city vulnerable to wintertime forms of EP as well as to climate change-related heat waves in the summertime. In the years 2016-2017, 24.7\% of the metropolitan population was at risk of poverty or social exclusion and $5.3 \%$ suffered severe material deprivation. Estimates based on EP indicators show that several hundred thousand people living in the metropolitan area experience difficulties in paying for their domestic water and energy are unable to keep their homes adequately warm in winter, reported arrears on utility bills or relied on insecure access to the supply of basic household utilizes (electricity, water and gas). These various forms of monetary and material deprivation affect women disproportionately as they have lower salaries and pensions, more precarious jobs, less access to stable, quality housing, and poorer health than men [21].

Gender inequality is a risk factor that increases the vulnerability and probability of suffering from EP [22]. Petrova and Simcock [23] have identified two ways in which EP is differentially experienced along gender lines: household practices of responding to and resisting EP, and the emotional labor of living with EP. Sánchez-Guevara et al. [17] look into the feminization of EP through an analysis of gender inequalities in EP incidence in the city of Madrid, while also highlighting the scarcity of available gender-disaggregated data referred to EP. Other previous research $[17,23,24]$ also suggests that one of the main problems to characterize and quantify the feminization of EP is the lack of gender-disaggregated data, since EP has typically been conceptualized and researched as a "household" issue.

It is well established that the physical health and psychological and emotional wellbeing of people can be influenced by their environment [25]. Over the last decade, there has been an increase in scientific publications that establish the relationship between inadequate housing and disease and mortality [26]. Studies such as the one conducted by Bonnefoy [27] explores the type of housing conditions that have a negative effect on occupants' health, and their associated risks. In the case of EP, affected persons are more 
likely to suffer from poor health because of their precarious socioeconomic situation, inadequate living conditions and limited opportunities and challenges in balancing strained household budgets. Critical drivers of ill-health in relation to EP are poor thermal and humidity conditions, inadequate dwelling quality, inability to afford domestic energy services and debt-related stress and social stigma, among others [28-32]. EP has severe direct and indirect impacts on the physical and mental health of those who suffer from it and these conditions have been associated with excess winter mortality and morbidity due to respiratory and cardiovascular diseases [33]; poor mental health and wellbeing [34]; and the exacerbation of existing health conditions. Furthermore, EP has been found to impact the ability of people to socially engage with others [16].

The recognition of EP as a distinct form of deprivation and as a policy issue of its own merit has triggered action in the EU at all levels over the last 10 years. Some of this action takes place under Horizon 2020-funded projects such as EmpowerMed (from which this paper stems) and cognate initiatives (such as REACH, ENPOR or STEP) that test approaches for addressing EP at small scales. These projects often include local interventions aimed at helping affected people save energy at home; an approach that often relies on changing habits and behavior under the assumption that people in EP use more energy than necessary due to the inefficiency of the dwelling or appliances and what has been labeled as "energy illiteracy" (i.e., "the lack of understanding of the nature and role of energy in our daily lives, and the inability to apply it to everything from making energy efficiency decisions to understanding energy bills" [35]). In many cases, interventions consist of household visits in which a rapid energy audit is conducted along with the provision of energy-saving and thermal comfort tips, and the installation of low-cost energy efficiency measures, e.g., LED bulbs, socket strips and simple windows weather-stripping. Such small-scale project-based interventions take place in parallel to more ambitious national and local level measures led by governmental actors to mitigate EP. For instance, Kyprianou et al. [6] have compared support policies implemented in five EU member states-Bulgaria, Cyprus, Lithuania, Portugal, Spain-Regarding consumer protection, financial interventions, energy savings, RES integration, and information provision. Initiatives led by non-governmental organizations have also been reviewed by Bouzarovski et al. [7] and Creutzfeldt et al. [36], for instance, the "CAF-Acció" initiative in Spain that lend EP-affected money to implement energy efficiency or retrofitting measures. Nonetheless, detailed information about their approaches, beneficiaries' characteristics or impacts on affected households is often missing in national-level studies of this sort.

In its Barcelona pilot site, the EmpowerMed project is testing and implementing collective advisory assemblies (CAA) as an innovative, collaborative empowering engagement tool that offers an alternative to traditional one-off individual household advice and support approaches. Inspired by right to energy principles, CAAs go beyond a symptomatic treatment of EP and aim to mobilize the potential of individual and collective agency for affected people-Especially women-To confront their "vulnerable consumer" status. They are based on a horizontal participatory methodology in which people affected by EP receive recurrent advice and support from an "assembly of peers"-A mix of activists and participants who have been or still are in EP themselves. As part of the EmpowerMed project activities, CAAs take place together with related forms of support (Figure 1), namely: (1) an electricity and indoor environmental comfort monitoring campaign to optimize electricity supply contracts and provide recommendations for comfort improvement; and (2) mutual support workshops facilitated by a counselor for addressing the mental health and emotional wellbeing impacts of EP. In that context, the authors want to give an answer to the following research questions:

- Who attends the CAAs and what is their socioeconomic profile?

- What are the indoor environmental comfort conditions of EP participants in CAA, in terms of thermal comfort and air quality? What are the differences when compared to non-EP households? 
- What electricity consumption patterns can be observed among EP-affected participants in CAA? What are the differences when compared to non-EP households?

- Are collaborative engagement tools such as CAA useful strategies to empower EPaffected persons and reduce the impact of EP?
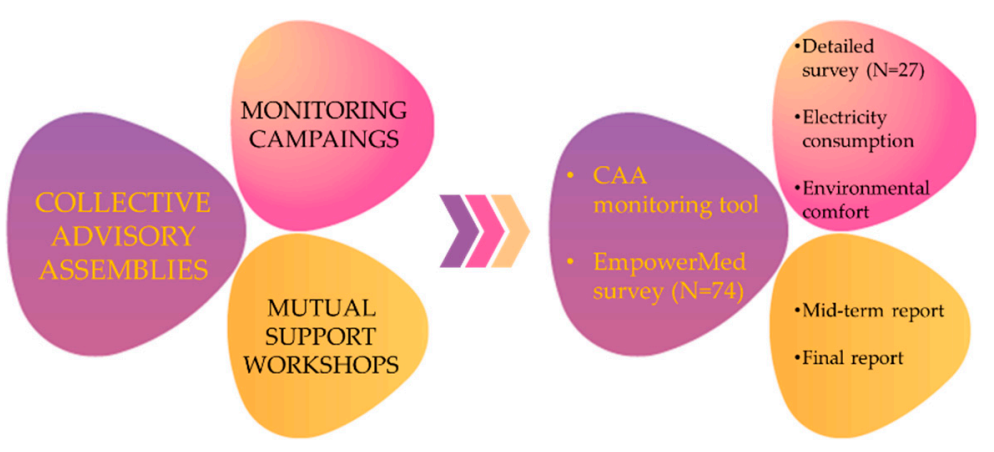

Figure 1. EmpowerMed activities (left) carried out in Barcelona pilot site and datasets (right) collected in each of them: collective advisory assemblies, monitoring campaign of electricity and indoor environmental comfort, and mutual support workshops.

The present work characterizes the EP population that attends CAA, describes and analyzes the results of EmpowerMed interventions from a multi-perspective point of view (energy use, economic savings, thermal comfort and indoor air quality, and empowerment of EP-affected population). The paper also produces a comparison of key EP-related variables in a small sample of EP households and non-EP-affected households. The analysis of the mutual support workshops is outside the scope of the paper, and only a short description of the activity is included.

The present paper is divided into the following sections: Section 2 describes the main determinants of EP in Spain, followed by Section 3 that introduces the social movement Alliance against Energy Poverty (APE) in Catalonia, in collaboration with which the EmpowerMed activities are carried out. Section 4 describes the materials and methods used in this research-in particular, data collection, tools and procedures. Section 5 shows the results of the research in relation to socioeconomic characterization of CAA participants, indoor environmental comfort, electric consumption and costs, and the achievements of the CAAs carried out in the framework of APE's actions; Section 6 discusses the results and relates the main findings to previous studies and is followed by Section 7 that states the main conclusions of the research.

\section{Energy Poverty Determinants in Spain}

It is well established that the determinants of EP are a combination of: (a) socioeconomic situation of the household; (b) poor housing energy efficiency; and (c) high energy prices [5]. To contextualize the Spanish situation in relation to EP driving factors, the main characteristics of the electricity market and the residential building stock are described below.

Household consumers in Spain have the option to get their electricity supply from a regulated or non-regulated company since the market liberalization process was completed with the enactment of the Electricity Service Law in 2013 [37]. Although one of the objectives of the market liberalization was to offer more competitive prices to consumers, electricity costs for Spanish households have followed an increasing trend in the past decade, even with the drop-in prices experienced in 2019 and 2020, as Figure 2-left shows. Spain is in fact one of the EU-27 countries with the highest electricity prices, especially when using Purchasing Power Standard (PPS) for comparison (Figure 2-right). The PPS is an artificial common reference currency unit used by Eurostat which eliminates the differences in price and income levels between countries. The prices shown in Figure 2 correspond to an average domestic consumer (2500-5000 kWh/year). However, when observing the same 
Eurostat data for different electricity consumption bands, it is observed that households with the lowest annual consumption (under $1000 \mathrm{kWh} /$ year) pay up to two times more in average per kilowatt-hour consumed than those in the upper consumption band (above $15,000 \mathrm{kWh} /$ year), which suggests that tariff structures in Spain put a heavier burden on low-income households as reported by Haar [38].

Furthermore, the Spanish regulation considers not only the variable cost per kilowatthour consumed as shown above, but also a capacity term charged upon the contracted power defined by the user. According to SmartEn [39], only Italy, the Netherlands, Norway, Portugal and Sweden had a similar tariff structure in the EU by 2019. Until June 2021, the capacity charge could represent over $75 \%$ of the consumers' electricity bill depending on their consumption habits, one of the highest in Europe [Indra/Eurelectric].
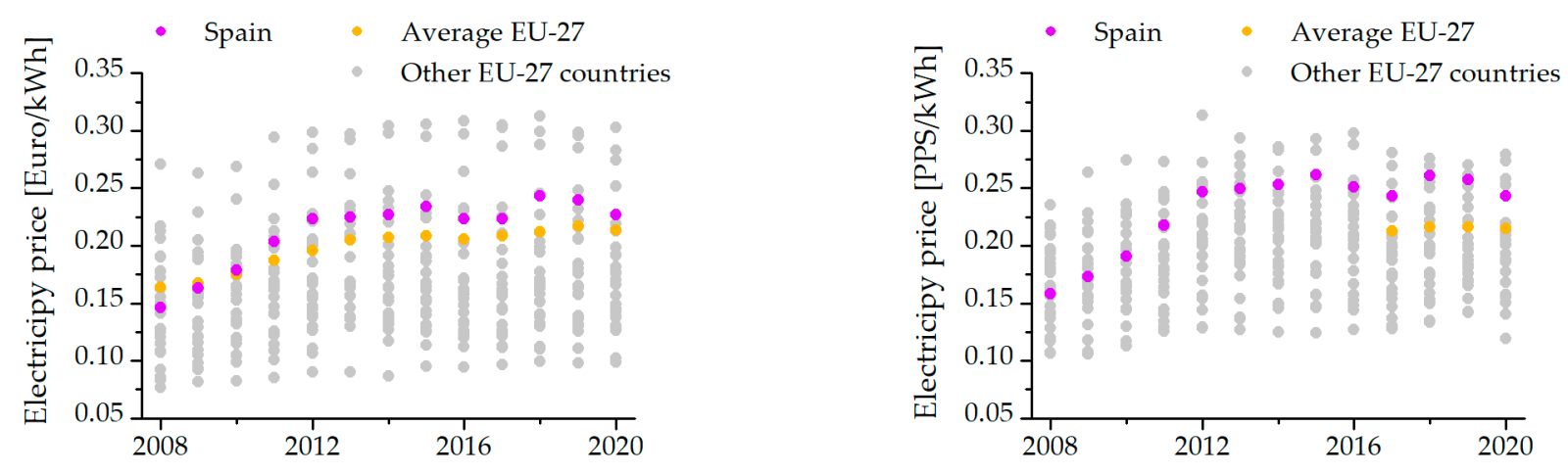

Figure 2. Electricity prices for household consumers in Spain and the European Union (27 countries), for a consumption band DC (Medium): Annual consumption between $2500 \mathrm{kWh}$ /year and $5000 \mathrm{kWh}$ /year. The prices include taxes and levies. Electricity prices in Euro/kWh (left) and in PPS/kWh (right) [40]. The EU-27 countries included are: BE, BG, CZ, DK, DE, EE, IE, GR, ES, FR, CRO, IT, CY, LV, LT, LU, HU, MT, NL, AU, PL, PT, RO, SI, SK, FI and SE.

To offer residential consumers an alternative from liberalized market supply contracts, the Spanish legislation allows low-voltage customers with contracted power under $15 \mathrm{~kW}$ to undertake their electricity from a reference supply company ("Comercializadoras de referencia", in Spanish), which are companies that can offer regulated tariffs under government price controls [41]. Before June 2021, three regulated tariffs were available under this scheme known as Voluntary Price for the Small Consumer (PVPC for its acronym in Spanish). Tariffs 2.0DHA and 2.0DHS could be classified as Time-of-Use (ToU) tariffs as they have more than one pricing period as explained in Circular 3/2014 [42], while tariff 2.0A was a flat rate. New legislation introduced in June 2021 [41] eliminates these three tariffs, leaving only one ToU tariff with three pricing periods (peak, valley, flat) available for customers in the regulated market.

Regarding national EP support policies, the status of vulnerable consumers and the social bonus ("Bono Social Eléctrico") for domestic electricity consumers were introduced in the late $2000 \mathrm{~s}$ and regulated in 2017 [43]. The social bonus is a social benefit that reduces the cost of electricity bill by $25 \%$ or $40 \%$ according to the level of vulnerability accredited by the beneficiary. Having a contract with a reference supply company is a requirement to access the social bonus. The household's vulnerability level is assessed by the government considering a series of socioeconomic characteristics such as annual household income, number of children, and special circumstances such as disability, status as victims of terrorism or gender-based violence 43].

Regarding the energy performance of buildings in Spain, more than $50 \%$ of the existing housing stock is over 50 years old [44], showing poor energy performance compared to the current building standards. The most common typology are buildings constructed between 1961 and 1980, which represent 36\% of the country's dwellings (6.4 million dwellings) and imply around $32.5 \%$ of the heating consumption of Spain [45]. This building typology was built without energy efficiency criteria, so it does not guarantee comfortable indoor 
conditions to the occupants without an intense use of heating and cooling systems (no insulation materials, low window performance, high infiltration and thermal bridges, inefficient heating systems). Statistical data from Eurostat's Survey on Income and Living Conditions (SILC) reflect these inadequate conditions of households, showing that as of 2019 around $7.5 \%$ of the Spanish population could not keep their home adequately warm in winter, $6.5 \%$ had arrears on utility bills or lived in a dwelling with a leaking roof, damp walls, floors or foundation, or rot in window frames of the floor. In addition, data from the EPOV indicate that $22.8 \%$ of the population lived in uncomfortable cool dwellings in the summer of 2012 and 14.2\% had had a high share of energy expenditure relative to their income [46].

\section{Alliance against Energy Poverty in Catalonia}

The Alliance against Energy Poverty (APE, "Aliança contra la Pobresa Energètica" in Catalan), formed in Catalonia in 2014, is a social movement, constituted by EP-affected people and activists. APE advocates for universal access to water and energy services, pointing out the responsibility of the administrations, but also of the large companies that trade with these services. Among APE's main battles is the prohibition of electricity, water and gas cuts in vulnerable households, the cancellation of debts incurred by these households with the utilities, the denunciation of the supply companies' harassment suffered by families in debt, and a guaranteed minimum level of supply for households in precarious housing conditions as a consequence of being forced to live in irregularly occupying properties.

A significant milestone of APE in Catalonia is Law 24/2015 [47] that prohibits supply cuts in "services of general interest" (i.e., water, gas and electricity) to vulnerable families, which was initially launched as a popular legislative initiative co-led by the Alliance. Since 2015, APE has been demanding big utility companies to cancel the accumulated debts of vulnerable families. Debt write-off was achieved for households indebted to the dominant water utility in the Metropolitan Area of Barcelona (Agbar) in 2018 and the dominant electricity company in Catalonia (Endesa) in 2021.

A primary tool in APE's action are CAAs, through which attendees share their own EP experience and receive the support and advice of the assembly. CAAs function as a transformative, self-support engagement methodology that helps participants facing often overwhelming EP conditions get rid of the fear, shame and sense of failure associated with EP. CAAs are held twice a month, followed by coordination meetings where political and strategic issues are discussed. In cases where it is deemed necessary, affected people are "accompanied" in the process of claiming their supply rights against utilities and public authorities. Non-violent direct actions and/or communication campaigns are also carried out within the framework of APE's political action strategy.

In CAAs, affected people (i.e., with unpaid rent or utility bills, or facing supply disconnection, foreclosure or eviction) share concerns and grievances in a safe and trusted space without feeling judged or examined. These meetings follow a collective intelligence methodology: As new cases arrive, knowledge accumulates and practical solutions to specific cases are jointly crafted by assembly participants, who also provide support and advice about, e.g., how to renegotiate a mortgage with a financial institution, or how to deal with utility providers and social services.

Assemblies have an explicit gender dimension as they are mostly attended by affected women. Even if assemblies are facilitated by non-affected activists, they purposely have no explicit formal leadership to ensure that everyone feels equally entitled to contribute with their knowledge and skills about, e.g., how to deal with utility companies, social services or how to change a supply contract to reduce bills (but not consumption). The individual household cases addressed in the CAA serve for advocacy purposes too. They allow disseminating the right to energy approach among the media and the wider public thus helping to insert this perspective into social imaginaries. 


\section{Materials and Methods}

\subsection{Data Collection}

Data collection was carried out within the framework of CAAs between October 2019 and May 2021. Consequently, a non-probabilistic sampling is used, where APE's participants were invited to voluntarily participate in the data collection process. Furthermore, social networks and email were used to engage non-EP-affected persons in order to compare their living conditions to the EP-affected ones.

Different levels of participation were proposed to CAA attendees, resulting in three datasets. A brief overview is presented and more details are provided in the next Sections 4.2 and 4.3:

- CAA monitoring tool: collects general information about each CAA. Information from 34 CAAs were registered during the studied period.

- CAA survey: Gathers information on socioeconomic and energy from all new CAA participants. 74 questionnaires were completed by assembly participants that attended a CAA for the first time.

- Monitoring campaign: detailed information is collected from 27 voluntary participants of the monitoring campaign, some of which were recruited during CAAs. This dataset contains thermal comfort, indoor air quality and electricity consumption data from 27 voluntarily surveyed households that include 14 EP-affected and 13 non-EPaffected households. However, due to specific characteristics of 8 of the 27 households (explained below), not all were included in the comparative analysis of electricity consumption. As a result, only 19 households are included in the electricity use assessment (10 EP-affected and 9 non-affected).

\subsection{Collective Advisory Assemblies (CAAs)}

Two different EmpowerMed tools for data collection are used in each CAA: The CAA monitoring tool and the CAA survey.

The CAA monitoring tool is used during the assemblies to obtain data in a nonintrusive way, as direct interactions that might disturb the session are avoided. This tool is formed by two simple tables through which an EmpowerMed project member takes notes of ongoing events and commentaries that take place during CAAs. The first table presents a general overview of the CAA by registering the number of persons (gender sensitive) that attend each session, present a case, speak out or inform of health affectations. The second table collects the characteristics of each individual case presented during the session. Specifically, the registered data are: Type of electricity contract (regulated or liberalized), contracted power, cost of the utility bill, active social bonuses for electricity and/or gas and other situations (e.g., water leaks, irregular connections or accumulated debts). In addition, the estimated potential savings of each form of support or advice provided by the assembly to the participant is included in the table. Once the session finishes, data are transposed to an Excel spreadsheet that automatically reports the expected and confirmed savings per session-See results in Section 5.4. An example of this tool is available at the website of the EmpowerMed project [48].

Regarding the CAA survey, all new participants to CAA, affected and non-affected, are invited to voluntarily fill in an online questionnaire that collects general socioeconomic and EP information of the households. The 74 household data are used to provide a descriptive analysis of EP-affected populations that participate in CAAs. Additionally, a correlation test is run on key survey variables using the Pearson correlation tool to find relevant statistical associations among variables-See results in Section 5.1.

\subsection{Monitoring Campaign: Electricity and Indoor Environmental Comfort}

A monitoring campaign is offered to CAAs' participants, addressed to EP-affected and non-effected. The monitoring campaign consists of four main parts, as Figure 3 shows: volunteer engagement, detailed monitoring survey, electricity and indoor environmental comfort monitoring campaign, individual and collective feedback. 


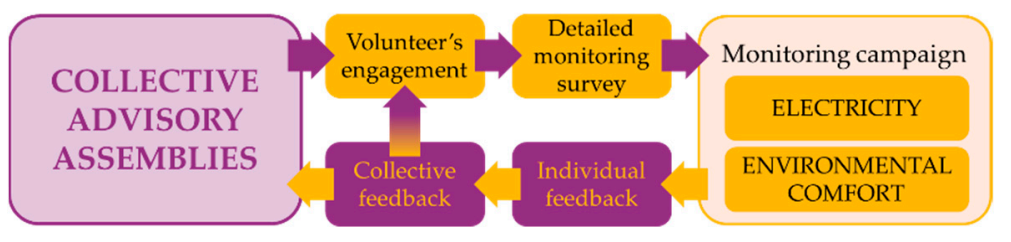

Figure 3. Monitoring campaign process: volunteer engagement, detailed monitoring survey, electricity and indoor environmental comfort monitoring campaign, individual and collective feedback.

The first step is to invite voluntary participants to take part in the monitoring campaign. This process is performed at two moments of the CAA:

- At the beginning of the assembly, when the monitoring campaign is introduced to the participants with the objective to involve them in the process.

- At the end of the assembly, when previous volunteers that have finished the monitoring process share their experience with the group, providing collective feedback and encouraging other people to participate in the monitoring campaign.

In the second step, volunteers proceed to complete a detailed monitoring survey [49]. The questionnaire collects information from different fields: Demographic and socioeconomic data, household information, comfort perception, energy supply contracts, EP indicators and energy awareness. A Google Form survey is used to deliver the questionnaire and is filled in in-person or online, depending on the volunteer's availability and also because of the COVID-19 pandemic restrictions.

During the third step, the monitoring process is carried out by collecting electrical and indoor environmental comfort data. A detailed explanation of both procedures is introduced in Sections 4.3.1 and 4.3.2.

The fourth step consists of providing feedback of the results and is performed once both monitoring processes are finished:

- Individual feedback: Volunteers receive an explanation about the results of the monitoring, which are summarized in two personalized reports. Some recommendations are provided in terms of the power supply contract and potential economic savings, as well as, thermal comfort and air quality improvements through basic behavioral changes.

- Collective feedback: Volunteers explain their experience during the monitoring campaign process at the CAA, highlighting the usefulness of the results and the easiness of its implementation.

\subsubsection{Indoor Environmental Comfort Monitoring}

The environmental comfort monitoring evaluates the thermal comfort and air quality through a measurement campaign of 10-15 days. Two sensors are given to each volunteer, with indications to place them in their living room and the main bedroom to record indoor air temperature, humidity and $\mathrm{CO}_{2}$ concentration. Data are recorded every 2-5 min, depending on the storage capacity of data loggers. Information about the sensors used in the monitoring process is detailed in Table 1 . The sensors are provided to volunteers completely configured along with simple instructions to place the sensors in their houses. The use of battery-powered sensors is prioritized, but plug-in sensors are provided to nonaffected volunteers when several households are monitored simultaneously. In general, the sensors are delivered during the CAA; however, a post-delivery service was available if needed to facilitate the participation of EP-affected people attending virtually to the CAA. Weather data are collected for the same monitoring periods from weather stations located in the vicinity of monitored households. 
Table 1. Characteristics of the sensors used in the monitoring process.

\begin{tabular}{cccc}
\hline Sensor & Variables & Power Supply & Location \\
\hline $\begin{array}{c}\text { Comet-U3430 } \\
\text { or }\end{array}$ & $\begin{array}{c}\text { Temperature } \\
\text { Humidity }\end{array}$ & Battery & Living room \\
Wöhler CDL 210 & $\mathrm{CO}_{2}$ concentration & Plug-in & \\
\hline Elitech RC-5 USB & Temperature & Battery & Bedroom \\
\hline
\end{tabular}

The monitored data together with the information from the detailed monitoring survey are used to analyze the indoor environmental comfort conditions of each household. The following aspects were used from the survey:

- Building characteristics: year of construction, state of conservation, level of energy efficiency and characteristics of the heating and cooling systems.

- Household size and usage of the dwelling: number of occupants, use of heating and cooling systems, use of natural ventilation and solar shading devices.

- Indoor environmental comfort perception: local discomfort issues in winter and summer, and satisfaction with indoor environmental comfort levels.

The monitored data were used to calculate the comfort and air quality indicators, in order to be compared with the users' comfort perceptions obtained from surveys. The indicators are described following and comfort ranges are detailed in Table 2:

- $\quad$ Operative Temperature $\left(T_{o p},{ }^{\circ} \mathrm{C}\right)$ is a thermal comfort index for adaptive method [50], that relates acceptable temperature ranges to weather conditions. The adaptive comfort method is applied in occupant-controlled naturally conditioned spaces.

$$
T_{o p}=A \cdot T_{i}+B \cdot T_{r m}
$$

where, $T_{i}$ is the indoor air temperature, $T_{r m}$ is the radiant mean temperature, and $A$ and $B$ are parameters that depends on the indoor air velocity $\left(v_{a}\right)$ (if $v_{a}<0.2 \mathrm{~m} / \mathrm{s}$, then $A=B=0.5$; if $0.2<v_{a}<0.6 \mathrm{~m} / \mathrm{s}$, then $A=0.6$ and $B=0.4$, if $v_{a}>0.6 \mathrm{~m} / \mathrm{s}$, then $A=0.7$ and $B=0.3$, which method for obtaining the operative temperature is described in ASHARE 55 [51]). Indoor air temperature is the only parameter measured, to simplify the campaign and do not disturb households' occupants, therefore the following assumptions were made: $T_{r m}=T_{i}$, and $v_{a}<0.2 \mathrm{~m} / \mathrm{s}$, and consequently the parameters $A$ and $B$ are 0.5 . These simplifications may underestimate the thermal discomfort of the users, as situations like radiant temperature asymmetry or draft are not completely reflected by the indoor air temperature parameter. However, a balance must be struck between the representativeness of the measurements and avoid inconvenience to users.

- $\mathrm{CO}_{2}$ concentration $\left(\mathrm{CO}_{2}, \mathrm{ppm}\right)$ is used as a tracer of human occupancy and allows to determine if the household has appropriate ventilation rates to guarantee acceptable indoor air quality.

As Table 2 shows, there are four comfort categories, from the highest to the lowest level of expectation, IEQ $_{\mathrm{I}}$ to IEQ $\mathrm{IV}_{\mathrm{IV}}$, respectively. The thermal comfort range is defined by a minimum and maximum comfortable operative temperature, which is established according to outside temperature conditions $\left(T_{0, r m}\right.$, running mean outdoor temperature of the daily mean outdoor air temperature). The measured operative temperature should be inside the corresponding comfort category, depending on the requirements of the users. For households, the expected comfort range would be IEQ II $_{\text {for new buildings and IEQ }}$ for existing buildings. The last comfort category, IEQ $\mathrm{IV}_{\mathrm{V}}$ should be avoided and is only acceptable for short periods of time. The air quality comfort ranges are based on the $\mathrm{CO}_{2}$ concentration, defining a maximum $\mathrm{CO}_{2}$ concentration above the outdoors for each category, being the outdoors $\mathrm{CO}_{2}$ concentration around $350-500 \mathrm{ppm}$. 
Table 2. Comfort range for the different comfort indexes: Operative temperature and $\mathrm{CO}_{2}$ concentration [50].

\begin{tabular}{|c|c|c|c|}
\hline Comfort Range & Level of Expectation & $\begin{array}{l}\mathrm{T}_{\mathbf{o p}} \\
{\left[{ }^{\circ} \mathrm{C}\right]}\end{array}$ & $\begin{array}{l}\mathrm{CO}_{2}^{(1)} \\
{[\mathrm{ppm}]}\end{array}$ \\
\hline $\mathrm{IEQ}_{\mathrm{I}}$ & $\begin{array}{l}\text { High. Occupants with special needs (children, } \\
\text { elderly, persons with disabilities, etc.). }\end{array}$ & $\begin{array}{c}T_{o p}=0.33 \cdot T_{o, r m}+18.8+2^{(2)} \\
T_{o p}=0.33 \cdot T_{o, r m}+18.8-3\end{array}$ & 550 \\
\hline IEQ $_{\text {II }}$ & Medium. Standard level. & $\begin{array}{l}T_{o p}=0.33 \cdot T_{o, r m}+18.8+3 \\
T_{o p}=0.33 \cdot T_{o, r m}+18.8-4\end{array}$ & 800 \\
\hline IEQ $_{\text {III }}$ & $\begin{array}{l}\text { Moderate. It will not provide any health risk but } \\
\text { may decrease comfort. }\end{array}$ & $\begin{array}{l}T_{o p}=0.33 \cdot T_{o, r m}+18.8+4 \\
T_{o p}=0.33 \cdot T_{o, r m}+18.8-5\end{array}$ & 1350 \\
\hline $\mathrm{IEQ}_{\mathrm{IV}}$ & $\begin{array}{l}\text { Low. Acceptable only for very short periods of } \\
\text { time throughout the year. }\end{array}$ & - & $>1350$ \\
\hline
\end{tabular}

(1) Corresponding $\mathrm{CO}_{2}$ concentration above outdoors (350-500 ppm). ${ }^{(2)} T_{0, r m}$ is the running mean outdoor temperature of the daily mean outdoor air temperature.

\subsubsection{Electricity Monitoring Tool}

The electricity monitoring tool consists of a Python script that calculates and compares the estimated annual electricity expenses considering different tariff options with the purpose of identifying the one that represents the least cost for the user and analysing whether they can opt for a social benefit to reduce their energy expenses or not. To do so, the tool requires information about the user's hourly electricity consumption, contracted power, maximum demanded power over the last year, current electricity supplier and tariff, as well as socioeconomic data.

The user's hourly electricity consumption data are downloaded as CSV files from their personal page at the distributor's website [52]. To create an account, the only requirements are being the electricity contract holder and having an official identification to validate their identity. The validation process takes over one day, so data are not immediately available. Aside from the hourly consumption data, the website indicates the name of the company supplying electricity to the user, their current tariff and contracted power. It also permits the visualization of the maximum demanded power registered each month since the electricity contract started.

The detailed monitoring survey is used to gather the users' socioeconomic data linked to social bonus granting. The annual electricity expenses are calculated considering available tariffs from the regulated and liberalized markets. To calculate the annual electricity expenses for the three tariff schemes available in the regulated market, the hourly active energy price for each $P V P C$ tariff $\left(P V P C E P_{h}\right.$, in EUR/kWh) is downloaded from the database of the Spanish Transmission System Operator (TSO), "Red Eléctrica Española" (REE) through their Advance Programming Interface (API) service [53]. The obtained values are multiplied by the corresponding hourly electricity consumption $\left(E C_{h}\right.$, in $\left.\mathrm{kWh}\right)$ as shown in the following equation, to get the total energy cost (TEC, in EUR):

$$
T E C=\sum_{h} P V P C E P_{h} \cdot E C_{h}
$$

The cost of the PVPCEP is formed by the transmission and distribution costs-Fixed per each pricing period-and the electricity production costs that vary every hour. Both concepts include other series of costs as explained in the Royal Decree 216/2014 [54]. Nonetheless, all of them are already considered in the PVPCEP value given by REE service.

The total power cost [TPC] is obtained by multiplying the user's contracted power $(U C P$, in $\mathrm{kW})$ per the sum of the annual contracted power cost $(A C P C)$, set at 38.043426 EUR/kW/year by the Order IET/107/2014 [55], plus an annual commercialization margin $(A C M)$ of 4 EUR $/ \mathrm{kW} /$ year [56]:

$$
T P C=U C P \cdot A C P C \cdot A C M
$$


The $5.1127 \%$ tax on electricity usage (EUT) is calculated upon the sum of the TEC and TPC values [56]. Afterward, the rental price of the smart meter $(S M R P)$ is added, considering a monthly cost of 0.84 EUR/month as stated by the Spanish Ministry of Energy, Tourism and Digital Agenda. Finally, the total annual electricity bill [TAEB] is obtained by calculating the value-added $\operatorname{tax}(V A T)-21 \%$-Upon the resulting amount [56] as shown in Equation (3).

$$
T A E B=V A T \cdot[E U T \cdot(T E C+T P C)+S M R P]
$$

For unregulated tariffs, it is not possible to obtain the same degree of accuracy because there are multiple options available and their costs change with time. Thus, the price paid by one customer might not be the same as another even if they hired the same option from the same company depending on when the contract was signed. For this reason, a benchmarking analysis is conducted obtaining the prices offered by 11 private companies for the concept of energy consumption (equivalent to the PVPCEP) and contracted power (equivalent to the sum of $A C P C$ and $A C M$ ). These were obtained from the companies' websites throughout June 2020 and can be consulted in Appendix A. The rest of the concepts are handled similarly to the PVPC scheme.

The resulting TAEB for each tariff-Regulated and non-regulated-Are compared by the tool, selecting the one that offers the minimum value. Additionally, the tool analyzes the user's responses to the detailed monitoring survey to establish the annual income threshold and the level of vulnerability applicable following the guidelines stated in the Royal Decree 897/2017 [43]. If the users' reported annual income is below the established threshold, the tool calculates the estimated annual savings they can achieve if the social bonus is applied, considering the discount percentage applicable for each case. When a user indicates to be a social bonus beneficiary, the tool applies the discount directly over the TAEB values. In all cases, the discount is applied only to the regulated market options.

The monitoring tool also compares the reported contracted power against the maximum demanded power. If the latter value is lower than the contracted power, the tool suggests contracting a power equivalent to 1.05 times the maximum demanded power. When the maximum demanded power is higher, the tool does not suggest changing their contracted value as it is assumed that users are not willing to pay more for their electricity services and prefer to deal with minor adjustments in their energy usage.

\subsection{Mutual Support Workshops}

The mutual support workshop is a group established by APE to tackle the emotional and mental health dimensions of EP. Not being able to keep the home at an adequate temperature, pay the bills or, at least, secure regular access to basic supplies, generates strong feelings of anxiety, impotence and guilt in families. Moreover, these families are forced to deal with these issues individually and often feel stigmatized and unsupported. The purpose of the mutual support workshop is to address those situations collectively and politically, with the main objective of alleviating the responsibility that families currently feel, based on the idea that accessing basic supplies is a right and should never depend on the ability to pay.

The mutual support workshop is an empowerment tool focused on health issues, based on an exchange of experiences and worries. It is carried out in the form of the gathering of a reduced group of people, building trust and a secure environment and that allows establishing strong relationships between participants. The purpose of the group is to jointly deal with some of the main inequity axes that accompany the EP: material and economic situations, gender, age, functional diversity, and health, among others.

Mutual support sessions are usually made up of a round on "How are we?" to open up into experiences that generate anxiety, pain, sadness, depression, anger that cannot be easily dealt with in the CAA. It follows a peer support dynamic through which participants have already experienced or felt the same situation/feeling and can empathize with others. That connection helps generate encouragement, support and positive reinforcement. Additionally, at the moment where a situation of human rights violation is shared, recognition 
and visibility take place because the situation is given voice and value. At the same time, the sessions act as a tool to take care of the group members' health. Self-organized care and monitoring mechanisms are established for group members that need it, or whatever roles need to be established to guarantee such support.

\section{Results}

\subsection{Socioeconomic Characterization of the Participants}

People attending CAAs in Barcelona constitute a severely affected EP population as indicated by the responses of the 74 assembly participants collected through the CAA survey between January 2020 and May 2021. As shown in Table 3, 82\% of survey respondents are registered in the social services system and $36 \%$ are at risk of housing exclusion as per the criteria of municipal social services. The latter means that they have an IRER ("Informe de Risc d'Exclusió Residencial", in Catalan), a socioeconomic vulnerability certificate issued by social services that protect vulnerable households from utility supply disconnections and evictions in accordance with Catalan Law 24/2015 [47]. Most people live in rented properties ( $49 \%$ of the total) and almost one-third of the respondents inhabit irregularly occupied dwellings (35\%). Such numbers suggest high levels of housing insecurity as these cases refer to families at risk of eviction and with other difficulties associated with their irregular housing circumstances, e.g., being denied an official utility supply contract. More than half of the respondents (54\%) experienced poor thermal comfort conditions at home and all reported issues related to access or affordability of basic utility supplies (water, electricity, natural gas-and butane gas in a few cases as well). Most respondents acknowledge that they struggle with two $(28 \%)$ or three $(50 \%)$ of those supplies. Still, only a few of them have access to social bonuses to reduce their expenditures on water, electricity or gas $(16 \%, 22 \%$ and $23 \%$, respectively). Our analysis found a significant correlation between having the social bonus for electricity and the social bonus for water $(r=0.78$, $p<0.01)$.

Regarding gender, more women (64\%) than men (35\%) seek support through CAA, which speaks of gender inequalities in the incidence of severe EP and also of gender differences in the way men and women respond to precarious living conditions. In addition, $43 \%$ of the respondents that attended the assemblies have children at home, while other vulnerable groups such as persons with disabilities are present in $24 \%$ of the households. Based on the correlation analysis, no strong associations between gender and other variables are found in the survey data, which might be due to the fact that all people answering the survey are affected by EP at some level. The gender factor, however, is present in the higher number of female respondents in comparison with their male counterparts.

The most significant issues reported by CAA participants are indebtedness with utility providers, supply disconnections and irregular connections to the supply (often associated with living in an irregularly occupied dwelling). These problems are acknowledged by as many as $45 \%$ of survey respondents (for any of the three supplies) and they are more likely to appear in relation to electricity (35\% of all cases) and water supply (27\%)-See Table 4 . It is observed that having an electricity supply contract is strongly positively correlated with having a water contract $(r=0.84, p<0.01)$ whereas having a gas supply contract positively correlates to having a water contract $(r=0.52, p<0.01)$, and an electricity contract $(r(72)=0.65, p<0.01)$. This is not surprising as the water supply is usually the most important utility service that household secure as it covers its most basic needs. Therefore, families that have other regular utility services like electricity or natural gas usually have access to a regular water supply as well. On the contrary, not all people that have a water contract manage to regularize their access to the supply of gas or electricity, especially when they live in an irregularly occupied property. The resulting correlation coefficients show that there are significant negative associations between living in an irregularly occupied home and having a water supply contract $(r=-0.51, p<0.01)$, having an electricity supply contract $(r=-0.67, p<0.01)$, and having a gas supply contract $(r=-0.59, p<0.01)$. This is expected as people in this situation face more challenges to regularize access to utility 
services. Finally, a positive correlation is found between having electricity debts and having water debts $(r=0.52, p<0.01)$, as well as, having electricity debts and gas debts $(r=0.59$, $p<0.01)$.

Table 3. Characteristics of participants in collective advisory assemblies (CAA survey, $n=74$ ) in January 2020-May 2021.

\begin{tabular}{|c|c|c|c|}
\hline Characteristics & & $n(\mathrm{~N}=74)$ & $\%$ of $n$ \\
\hline \multirow{3}{*}{ Gender } & Woman & 47 & $64 \%$ \\
\hline & Man & 26 & $35 \%$ \\
\hline & Non-binary & 1 & $1 \%$ \\
\hline \multicolumn{2}{|c|}{ Children in the household } & 32 & $43 \%$ \\
\hline \multicolumn{2}{|c|}{ People with disabilities in the household } & 18 & $24 \%$ \\
\hline \multirow{4}{*}{ Housing tenure } & Owned & 6 & $8 \%$ \\
\hline & Rented & 36 & $49 \%$ \\
\hline & Irregularly occupied & 26 & $35 \%$ \\
\hline & Other & 6 & $8 \%$ \\
\hline \multirow{3}{*}{$\begin{array}{l}\text { Registered in social } \\
\text { services }\end{array}$} & Yes & 61 & $82 \%$ \\
\hline & No & 9 & $12 \%$ \\
\hline & Does not know & 2 & $3 \%$ \\
\hline \multirow{4}{*}{$\begin{array}{l}\text { At risk of housing } \\
\text { exclusion (IRER) }\end{array}$} & Yes & 27 & $36 \%$ \\
\hline & No & 25 & $34 \%$ \\
\hline & Did not qualify & 2 & $3 \%$ \\
\hline & $\begin{array}{c}\text { Does not know what } \\
\text { IRER is }\end{array}$ & 20 & $27 \%$ \\
\hline \multirow{3}{*}{$\begin{array}{c}\text { Access to Social } \\
\text { Bonus }\end{array}$} & Water & 12 & $16 \%$ \\
\hline & Electricity & 16 & $22 \%$ \\
\hline & Gas & 17 & $23 \%$ \\
\hline \multirow{2}{*}{$\begin{array}{l}\text { Thermal comfort at } \\
\text { home in winter }\end{array}$} & Uncomfortable & 40 & $54 \%$ \\
\hline & Comfortable & 28 & $38 \%$ \\
\hline \multirow{7}{*}{$\begin{array}{l}\text { Reports EP related } \\
\text { issues with utility } \\
\text { supplies }\end{array}$} & Water & 63 & $85 \%$ \\
\hline & Electricity & 56 & $76 \%$ \\
\hline & Gas & 42 & $57 \%$ \\
\hline & Butane & 3 & $4 \%$ \\
\hline & One supply & 14 & $19 \%$ \\
\hline & Two & 21 & $28 \%$ \\
\hline & Three & 37 & $50 \%$ \\
\hline
\end{tabular}

Table 4. EP-related issues reported by participants in collective advisory assemblies $(n=74)$ in January 2020-May 2021.

\begin{tabular}{cccc}
\hline Percentage of Participants & Water & Electricity & Natural Gas \\
\hline Irregular connection to the supply & $11 \%$ & $16 \%$ & $4 \%$ \\
\hline Outstanding debt with provider & $11 \%$ & $18 \%$ & $12 \%$ \\
\hline Had supply disconnection & $8 \%$ & $7 \%$ & $1 \%$ \\
\hline Any of the above & $27 \%$ & $35 \%$ & $16 \%$ \\
\hline
\end{tabular}


EmpowerMed data also allow for comparison among EP and non-EP-affected people. Table 5 presents the results of the detailed monitoring survey of a subsample of 27 households (14 assembly participants affected by EP vs. 13 voluntary households not affected by EP) that took part in the EmpowerMed monitoring campaign between September 2020 and June 2021. Results indicate significantly higher levels of wintertime thermal discomfort among those affected by EP ( $93 \%$ vs. $46 \%$ ) but otherwise similar levels of summertime thermal discomfort (57\% vs. 54\%). More than half (64\%) of the EP-affected households declare arrears on utility bills in the last 12 months whereas zero non-EP households face this situation. EP-affected also displays a range of well-known coping behaviors such as cutting on food, medication or clothing expenditures; reducing water consumption, limiting the usage of appliances and white goods or indoor heating and lighting. In contrast, practically all non-EP households declare that they do not need to resort to any of these adaptive mechanisms to ensure they can pay utility bills. All in all, these values reflect broader socioeconomic inequalities between EP and non-EP-affected households as evidenced by the fact that the equivalised monthly income of non-EP households (EUR 1816) is more than three times higher than the equivalised income of EP-affected (EUR 515). Note that these equivalisation factors from the OECD-modified equivalence assign a value of 1 to the household head, of 0.5 to each additional adult member and of 0.3 to each child.

Table 5. Comparison of households affected (EP) and non-affected (non-EP) of a subsample of 27 households that take part in the EmpowerMed monitoring campaign.

\begin{tabular}{|c|c|c|}
\hline & EP & Non-EP \\
\hline \multirow{2}{*}{ Monthly income (EUR/equivalent person) } & EUR & EUR \\
\hline & 515 & 1816 \\
\hline Cannot keep home adequately warm in winter & $93 \%$ & $46 \%$ \\
\hline Cannot keep home adequately warm in summer & $57 \%$ & $54 \%$ \\
\hline Arrears on utility bills & $64 \%$ & $0 \%$ \\
\hline \multicolumn{3}{|l|}{ To make sure you could pay utility bills, have you had to ...? } \\
\hline cut on food expenditure & $43 \%$ & $0 \%$ \\
\hline reduce hot water consumption & $29 \%$ & $0 \%$ \\
\hline reduce water consumption & $36 \%$ & $0 \%$ \\
\hline cut on heating & $64 \%$ & $8 \%$ \\
\hline reduce natural gas consumption & $43 \%$ & $0 \%$ \\
\hline cut on indoor lighting & $64 \%$ & $0 \%$ \\
\hline reduce expenditure on medication or clothing & $57 \%$ & $0 \%$ \\
\hline shorten house ventilation time & $21 \%$ & $0 \%$ \\
\hline reduce the usage of appliances or white goods & $43 \%$ & $0 \%$ \\
\hline none of the above & $21 \%$ & $92 \%$ \\
\hline \multicolumn{3}{|l|}{ Participation in Collective Advisory Assemblies } \\
\hline Yes, more than 3 sessions & $64 \%$ & $31 \%$ \\
\hline Yes, less than 3 session & $36 \%$ & $8 \%$ \\
\hline No, never & - & $62 \%$ \\
\hline
\end{tabular}

\subsection{Indoor Environmental Comfort Evaluation}

Based on the data collected in the detailed monitoring survey $(n=27,14$ EP-affected and 13 non-affected), $74 \%$ of the households live in buildings constructed without any or with poor energy efficiency criteria (before 1979), including both EP and non-EP households. Additionally, $75 \%$ of the respondents report inadequate housing conditions, such as mold and dampness $(48 \%)$, water leaks $(11 \%)$, cracks in walls $(26 \%)$ or air leakage in windows 
and doors (63\%). Figure 4 indicates that butane heaters (36\%) and electric radiators (29\%) are the most common heating systems in EP-affected households, and that electric radiators (54\%) and natural gas boilers (38\%) dominate in non-EP households. Additionally, non-EP households tend to have more than one heating system ( $30 \%$ of non-EP households), in comparison with the EP households (one household, 7\%). In summer, most households do not use any mechanical cooling system (50\% in EP-affected households, and 38\% in non-EP), $21 \%$ and $31 \%$ use fans and $29 \%$ and $31 \%$ air conditioning in some of the rooms at their household, for EP and non-EP households, respectively. In both seasons and groups, the heating and cooling systems are used only when it is cold/hot and mainly in some rooms. Additionally, almost all households use natural ventilation in winter for cleaning the air (1.3 h/day on average), and in summer for refreshing the household (more than 5 h/day).

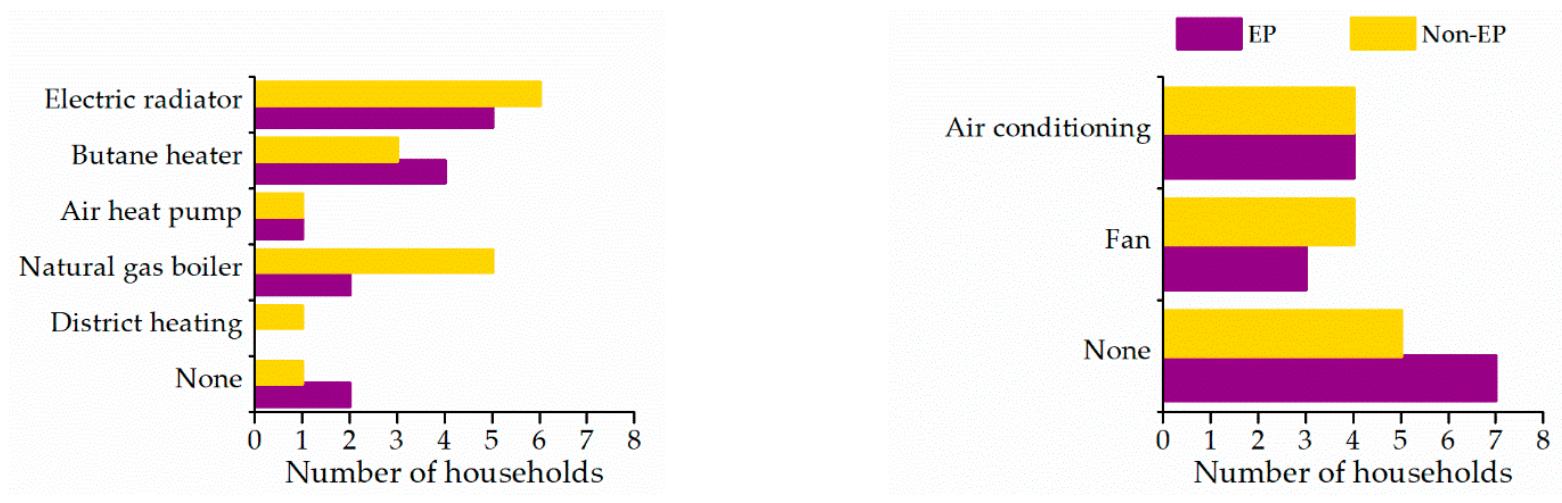

Figure 4. Heating (left) and cooling (right) systems used in EP and non-EP households.

After describing the main features of the households and their heating and cooling systems, indoor environmental comfort is evaluated using the participants' personal perception and the monitored data. Figure 5 shows the indoor environmental comfort perceptions of EP and non-EP respondents, with 10 representing the best comfort perception and 1 the worst. In general, non-EP households have higher satisfaction with the indoor environmental comfort (air quality, thermal, visual and acoustic comfort) of their homes with an average of 8 , in comparison with the average value of 5.4 for EP households. In terms of thermal comfort, the satisfaction is low in both groups, and worst for the EP persons, especially in winter. The EP-affected expresses an average dissatisfaction of 3.6 in winter and 5.3 in summer, while non-EP results in 5.7 and 6.3, respectively. In relation to visual comfort, for daylighting and artificial lighting, comfort perception is around 7 in EP households, and around 8 for non-EP.

Figures 6 and 7 analyze the operative temperature of the living room from EP (left) and non-EP (right) households. In Figure 6, the operative temperature of each household is represented together with the mean outdoor temperature (grey dots), showing when the indoor conditions provide comfort to the users based on the adaptive model categories presented in Table 2. Additionally, the average operative temperature of the monitored period is represented (purple and yellow dots). It is possible to observe that, most of the time, EP and non-EP-affected are at least in Category III (IEQ III). However, two EP households (those at the bottom of Figure 6-left) were monitored during an extreme weather conditions period (Filomena Storm, 8-10 January 2021) and most of their monitored operative temperature data are outside category III (IEQ $\left.{ }_{\text {III }}\right)$, providing an average operative temperature around $15^{\circ} \mathrm{C}$. 

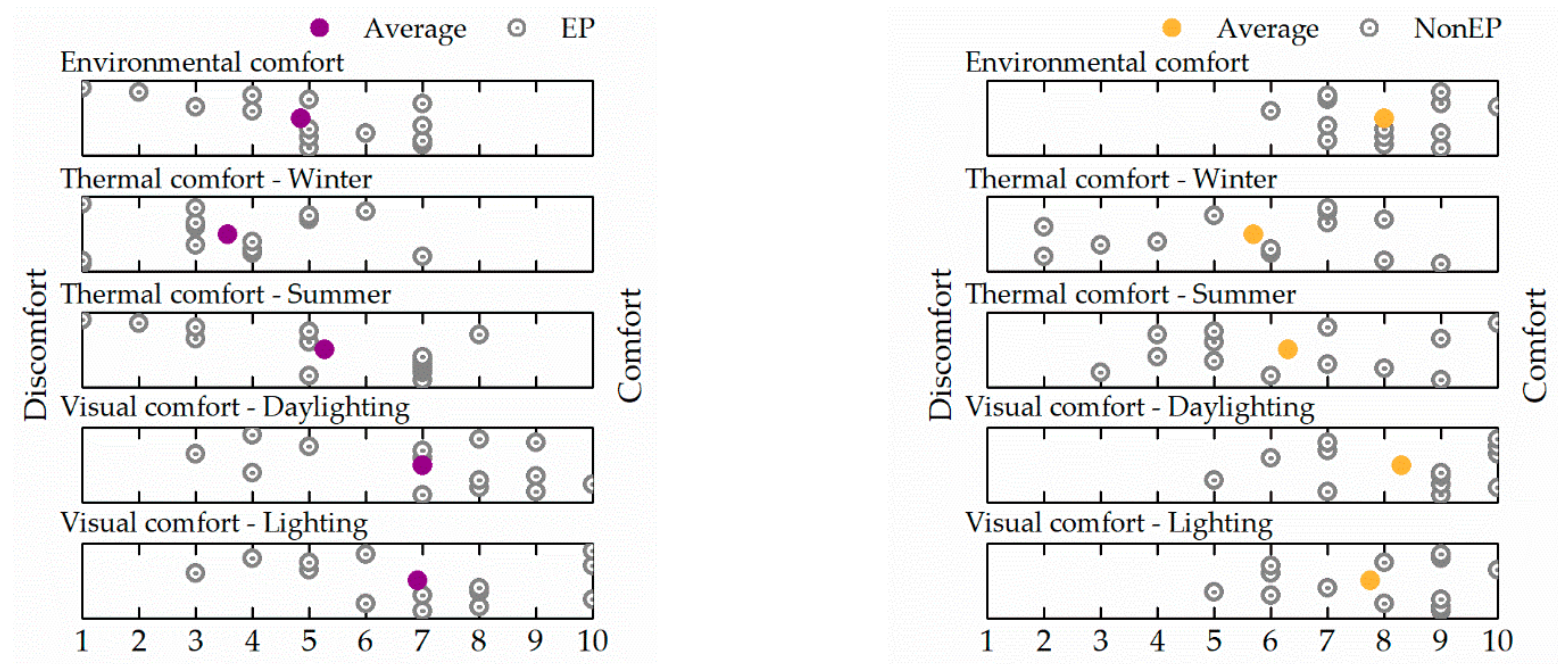

Figure 5. Indoor environmental comfort perception of EP (left) and non-EP (right) affected persons, being 1 discomfort and 10 comfort. Grey dots represent the answers of each person, and purple/yellow dots are the average value of EP and non-EP, respectively.
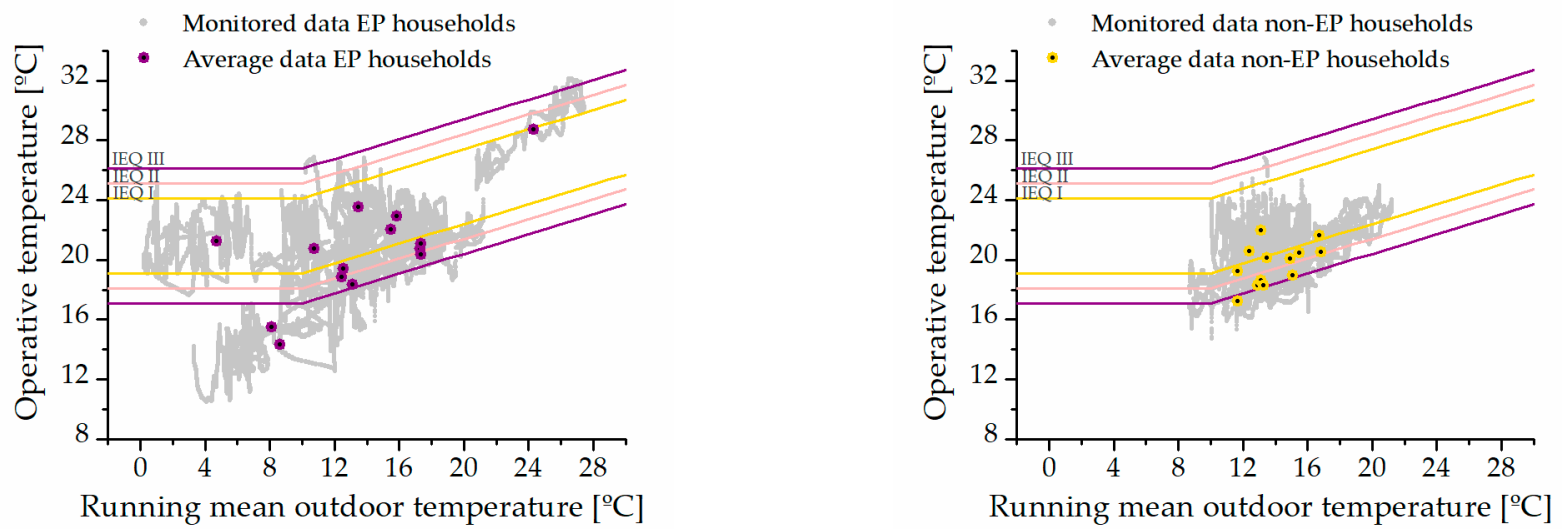

Figure 6. Indoor operative temperature of EP (left) and non-EP (right) households as a function of running mean outdoor temperature. Thermal comfort categories (IEQ) based on adaptive model.
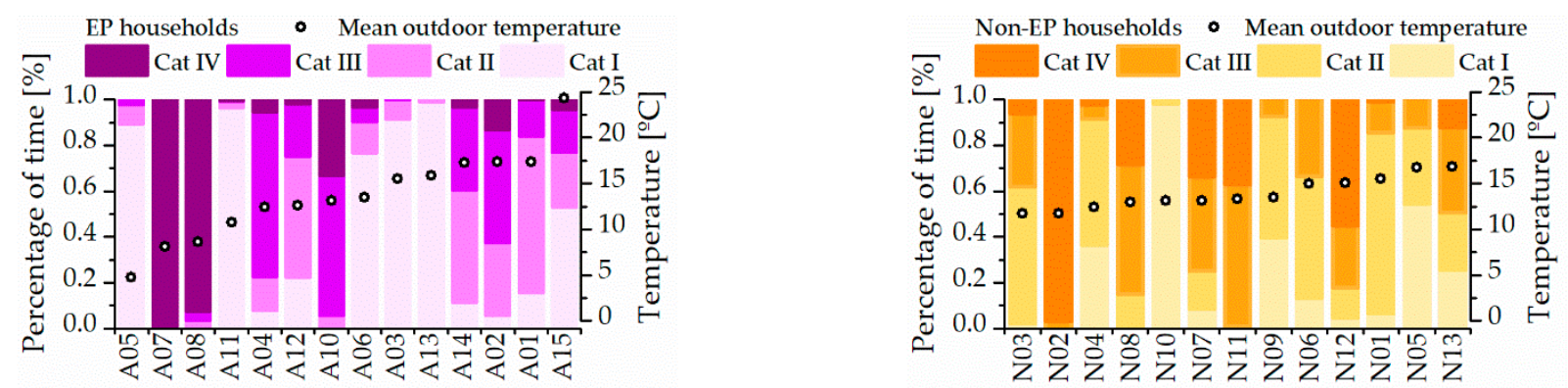

Figure 7. Percentage of time in each thermal comfort category based on an adaptive model for each EP (left) and non-EP (right) households. Monitored households are srted by mean outdoor temperature, represented by a holed dot (right axes).

Figure 7 represents the percentage of time when the operative temperature is inside each comfort category, confirming that there are not many differences between both groups of households. Around 3-5 households of each group spend more than $20 \%$ of the monitored time with operative temperatures in Category IV (IEQ ${ }_{I V}$ ), which is only acceptable for very short periods of time. Comparing the monitored temperature of the living room and the bedroom, there is a difference between both $\left(0.5-2{ }^{\circ} \mathrm{C}\right)$, with living room temperatures being higher for most of the households. 
Figure 8 represents the air quality of the monitored households, EP and non-EP (left and right, respectively). The air quality is evaluated through the $\mathrm{CO}_{2}$ concentration and the percentage of time when households are in each air quality category. There are significant differences between both groups, with the EP-affected households reporting poorer air quality: nine EP households spend more than $20 \%$ of the time in Category III (IEQ III) or worse, in comparison with only five non-EP households. One possible reason could be that around $86 \%$ of the EP-affected households are occupied almost the entire day, in comparison with just $46 \%$ of non-EP households with this dwelling usage regime. Additionally, a clear relationship can be observed between heating systems and air quality: households using butane heaters that were monitored in cold periods present very low air quality, being around $60-80 \%$ of the time in IEQ A08). The remaining households with butane heaters (A09, A14, N07, N12, N13) do not reflect the same behaviour probably due to warmer weather conditions of the monitored period that require less use of heating.
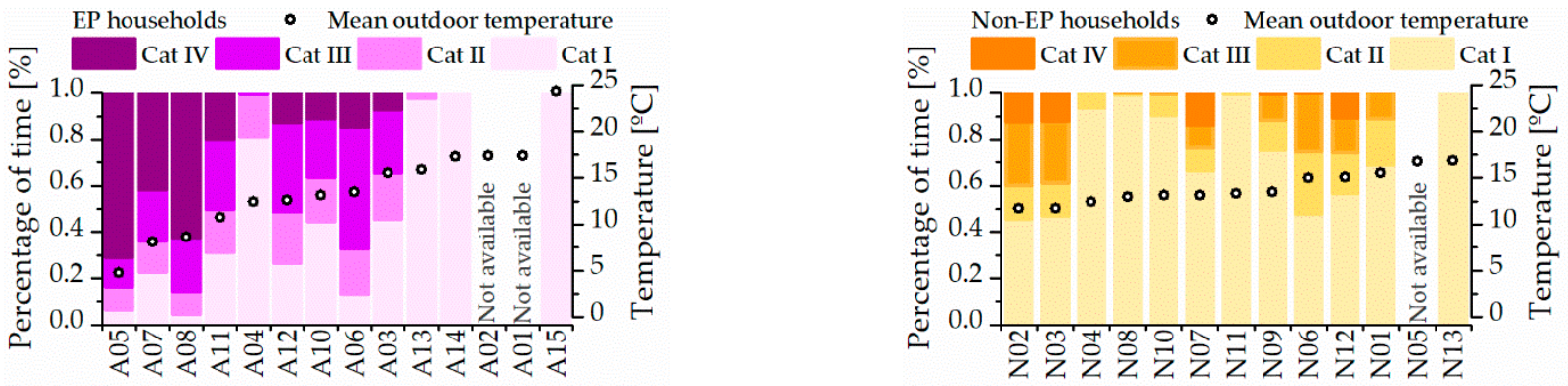

Figure 8. Percentage of time in each air quality category based on $\mathrm{CO}_{2}$ concentration for each EP (left) and non-EP (right) household. Monitored households are sorted by mean outdoor temperature, represented by a holed dot (right axes).

\subsection{Electricity Consumption and Cost}

For the assessment of the electricity consumption monitoring campaign, 19 out of the 27 households participating in the monitoring campaign are evaluated using the electricity monitoring tool. Eight are excluded from this part of the study due to the lack of sufficient data caused by smart-meter malfunction, shorter contract validity period or irregular electricity supply access conditions. From the 19 evaluated households, 10 participate in CAAs and are affected by EP, while the remaining 9 are non-EP-affected households whose data are collected with the purpose of comparing their consumption and electricity expenses against EP-affected users.

Relevant characteristics of the electricity contract held by each household are presented in Table 6. Most EP-affected households have a regulated tariff contract as this is a requirement to access the social bonus discount, a form of support from which $70 \%$ of the evaluated nine EP households already benefit. According to the survey responses, $80 \%$ of the monitored EP group have also already applied and obtained the IRER. The detailed monitoring survey responses show that EP users with regulated tariff contracts and social bonuses had attended at least three CAAs, whereas those new to the APE are more likely to have an unregulated supply company contract and none of them had the social bonus by the time they first come to a CAA. Notably, none of the non-EP households have a regulated tariff contract even considering it is usually cheaper [57], but otherwise, they have ToU tariffs in a slightly higher percentage than EP users. 
Table 6. Characteristics of the electricity contract held by EP and non-EP households.

\begin{tabular}{ccc}
\hline Metric & EP & Non-EP \\
\hline Percentage of households with a regulated utility company [\%] & $90.0 \%$ & $0 \%$ \\
\hline Percentage of households with ToU tariff [\%] & $60.0 \%$ & $66.7 \%$ \\
\hline Percentage of households with the social bonus discount [\%] & $70.0 \%$ & $0 \%$ \\
\hline Average contracted power [kW] & 3.19 & 4.17 \\
\hline
\end{tabular}

Regarding the analysis of the households' annual electricity consumption, Figure 9-left, shows some differences between EP and non-EP households. First, the average annual consumption per household in the EP group ( $2451 \mathrm{kWh} /$ year) is $3 \%$ lower than the value reported for the non-EP group ( $2535 \mathrm{kWh} /$ year). When calculating the average annual consumption per equivalent person the differences between both groups rise up to $8 \%$, but remain lower for the EP group ( $1443 \mathrm{kWh} /$ year) as compared to the non-EP (1575 kWh/year). It should be noted that for both indicators there is a higher variation among the EP group's values. The higher electricity consumption values in both subsamples correspond to 3-5-member families. This households' values get closer to the group's median when looking at the equivalent-person metric. Figure 9-right represents the distribution of contracted power for each household, showing significant differences among EP and non-EP. The EP households have on average a contracted power of $3.2 \mathrm{~kW}$, while non-EP households tend to have higher contracted power, with an average of $4.2 \mathrm{~kW}$.
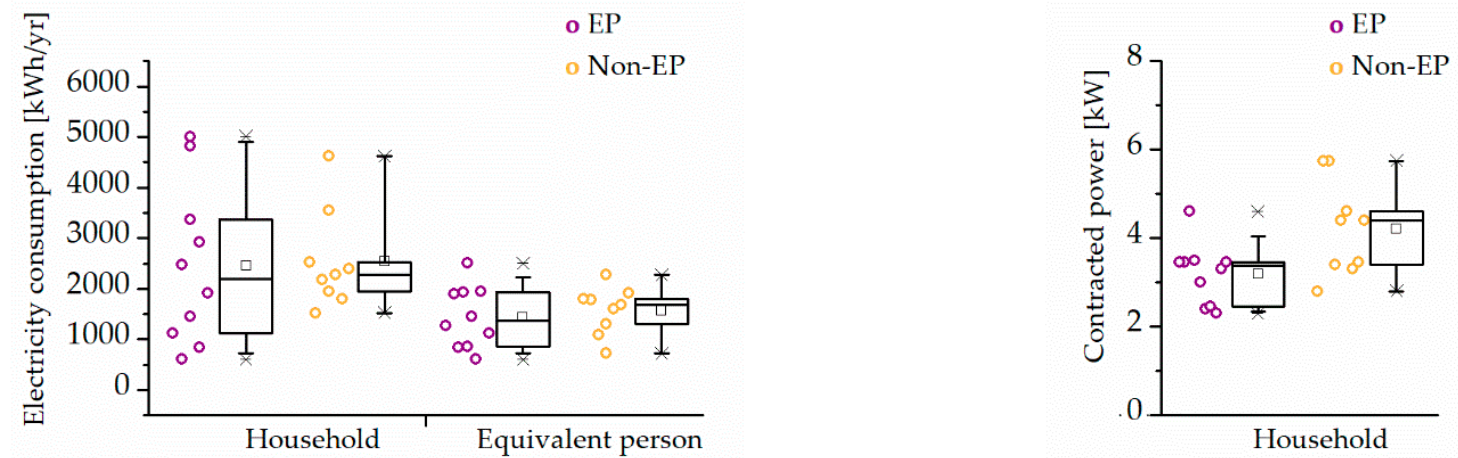

Figure 9. Box plots showing the annual consumptions per household and equivalent person (left) and contracted power (right) for EP and non-EP households. Description of the box plot parameters: mean by square; median by horizontal line; $25-75 \%$ percentile by box; $10 \%$ and $90 \%$ by whiskers; $1 \%$ and $99 \%$ percentile by cross; minimum and maximum by dash.

A significant difference between groups can be observed when analyzing electricity consumption by season. Figure 10 represents the monthly electricity consumption per equivalent person of each household (grey lines) and the average for EP and non-EP households (purple and yellow dotted lines, respectively). In general terms, the average electricity consumption for the EP curve is flatter than for non-affected households, and indicates similar monthly values in winter than in summer. On the other hand, the values of non-EP households reveal an important variation of consumption between winter and summer, being higher in winter and lower between May and November. As it happens with annual values, households in the EP group show higher diversity among individual consumption patterns than in the non-EP group. 


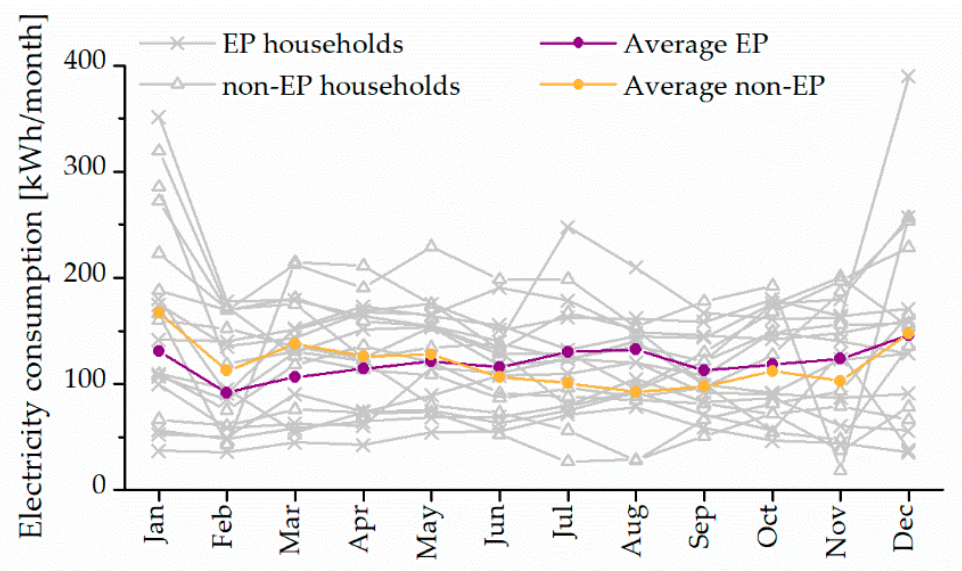

Figure 10. Monthly electricity consumption per equivalent person for EP and non-EP households.

To better understand the seasonal impact on the consumption habits, the hourly electricity consumption per equivalent person for two average days representing summer and winter seasons are calculated. To this end, the monitored consumption data registered in the months of January (winter) and July (summer) are used, as Figure 11 shows. The average winter day reveals large differences between non-EP and EP households, having a similar shape but with a lower magnitude. The non-EP households have a more pronounced peak in the morning and in the evening, reflecting their working time schedule. In both groups, the maximum consumption is registered at $22 \mathrm{~h}$, with a value of $0.42 \mathrm{kWh}$ for non-EP households and $0.31 \mathrm{kWh}$ for EP-affected. Night-hours consumption is very similar in both groups. Looking at the entire groups' average consumption in July, it is observed that non-EP-affected consumption remains mostly flat during the day, while EP-affected households show a consumption peak around $10 \mathrm{~h}, 16 \mathrm{~h}$ and after $21 \mathrm{~h}$. However, as a difference of the winter day, the variation between EP and non-EP households is smaller.
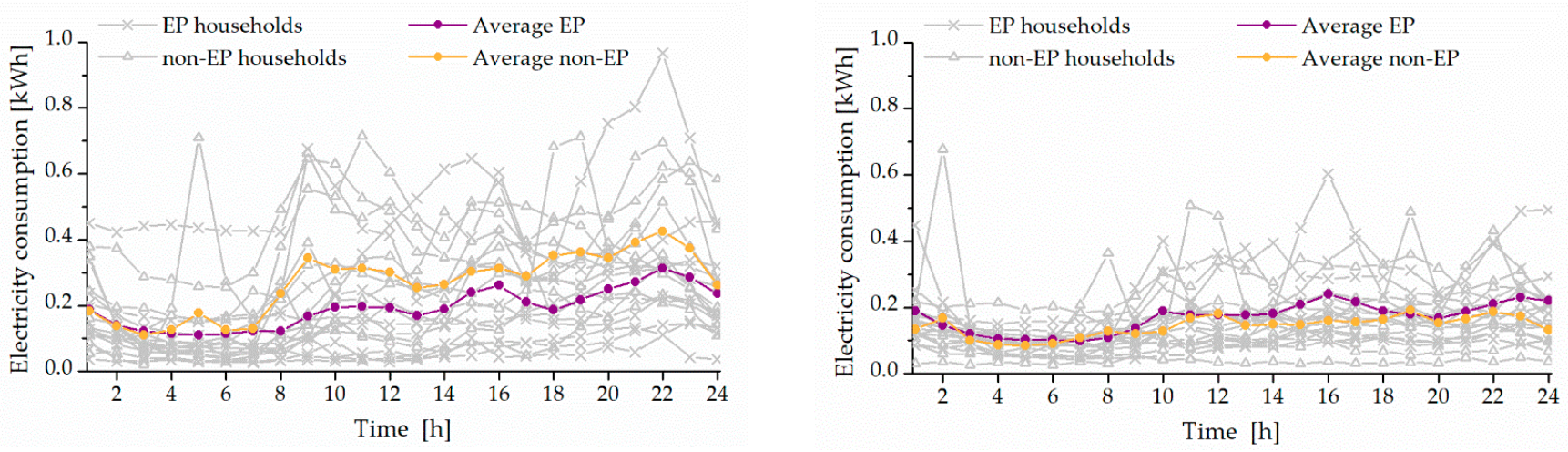

Figure 11. Hourly energy consumption per equivalent person for an average day in winter (left) and summer (right) seasons based on monitored data by EP and non-EP household for the months of January and July, respectively.

Regarding electricity expenses, Table 7 summarizes the obtained results through the electricity monitoring tool, and is not based on actual electricity bills. Electricity expenses from the non-EP households are found to be $26 \%$ higher than for EP households, and $63 \%$ if the social bonus is taken into consideration (only applied if a user meets the previously mentioned requirements). This is due to the more expensive contracts and higher contracted power in an average non-EP-affected group as compared to EP-affected households. In general terms, it is observed that affected households prefer regulated tariff contracts as they are less costly per $\mathrm{kWh}$ and give them access to the social bonus. In comparison, non-affected users value other aspects such as the possibility to consume 
electricity from renewable energies, that are offered by non-regulated companies (reported by $55 \%$ of non-EP households).

Table 7. Comparison of electricity expenses metrics between EP and non-EP households.

\begin{tabular}{|c|c|c|}
\hline Electricity Expenses Metrics ${ }^{1}$ & EP & Non-EP \\
\hline Average household electricity expenses without social bonus [EUR/yr] & 413.0 & 521.7 \\
\hline Average household electricity expenses considering social bonus ${ }^{2}$ [EUR/yr] & 320.7 & 521.7 \\
\hline Average percentage of electricity bill corresponding to contracted power [\%] & $52 \%$ & $57 \%$ \\
\hline Average cost reduction per household implementing changes suggested [EUR/yr] & 42.0 & 126.2 \\
\hline $\mathrm{N}^{\circ}$ of users recommended to change to a regulated contract & 1 & 9 \\
\hline $\mathrm{N}^{\circ}$ of users recommended to change from a flat to a ToU regulated tariff & 4 & 9 \\
\hline $\mathrm{N}^{\circ}$ of users recommended to lower their contracted power & 1 & 0 \\
\hline
\end{tabular}

${ }^{1}$ Calculated using the electricity monitoring tool described in Section 4.3 .2 and not based on actual electricity bills. ${ }^{2}$ The social bonus discount is applied only if a user meets the previously mentioned requirements.

The monitoring campaign indicates that there are opportunities to reduce electricity expenses in both groups; however, on average, the cost-saving potential is higher for the non-EP group ( $24 \%$ vs. $12 \%$ savings) as they tend to have costlier contracting conditions. The most common suggestion is changing from a free-market contract to a regulated tariff contract as the latter is the cheapest option for all analyzed users. As all non-affected households have unregulated contracts, the EmpoweMed tool suggests this option for more users in this category than in the EP, as only one household in it has this type of contract. In all cases, the recommendation also includes contracting a regulated ToU tariff.

Regarding contracted power, only one of the households in the EP-affected group has a contracted value above their needs and, therefore, an opportunity to save money by lowering it. On average, the cost associated with the contracted power represents a larger share of the electricity bill for non-EP consumers as they tend to contract higher power values at a costlier rate. It might be possible for some users to reduce their contracted power by implementing some changes in their consumption habits, but this analysis is not part of the study.

Another result of the analysis is that the flat regulated tariff $(2.0 \mathrm{DA})$ is not found to be optimal for any of the evaluated households. For this reason, the EmpowerMed tool recommends users with a flat regulated tariff changing to a ToU alternative-Until the change in legislation occurred in June 2021 (see Section 2). In general, the ToU tariff has lower prices at night (valley period) and higher prices during day-time (peak period), as represented in Figure 12-right. Moreover, the numbers obtained show in Figure 12-left that all households (no matter if they are affected or not) have a relatively balanced consumption with none of them having more than $57 \%$ of the consumption in a given period (peak or valley). 


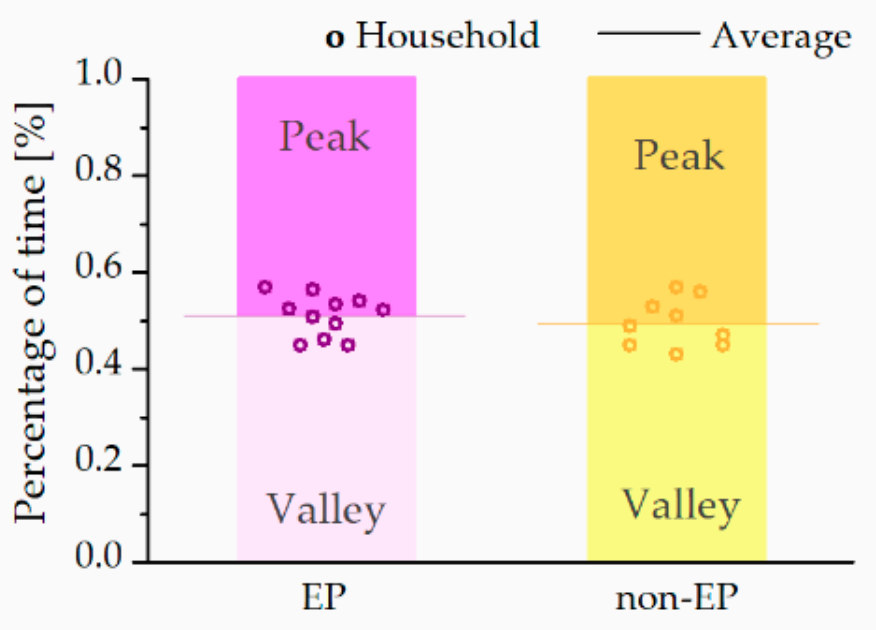

ToU tariff periods
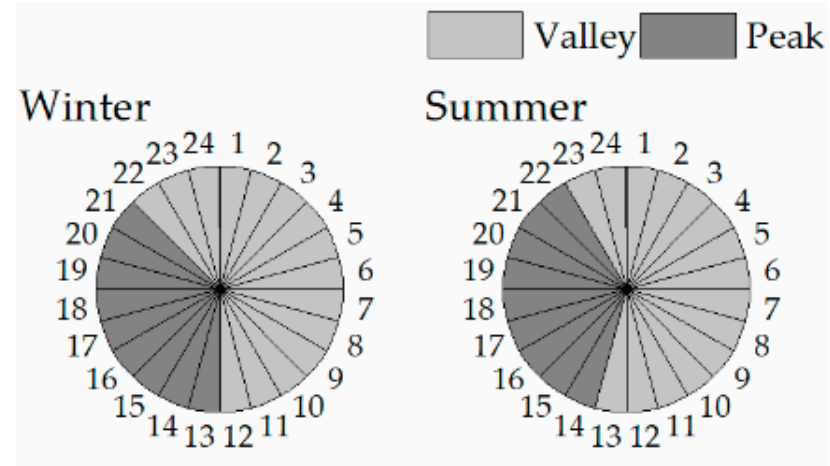

Figure 12. Distribution of annual consumption for each ToU tariff period (valley and peak) before the change legislation in June 2021. Left: The bar graph shows the average values per EP and non-EP households and the dots each household.

Right: ToU tariff periods definition in winter and summer.

\subsection{APE's Achievements through CAAs: Results of the CAA Monitoring Tool}

The EmpowerMed CAA monitoring tool reports 789 participants and 308 cases presented during 34 CAA held between October 2019 and May 2021: an average of 23 persons and 9 cases per assembly. Women are a majority in terms of CAA's participation (58\% of attendees and $61 \%$ of cases). They also report more often than men being the contract holder of the energy supply service (67\%) and be facing health impacts $(74 \%)$.

The overall expected savings obtained through the participation in CAAs is estimated at EUR 17,472, about EUR 514 per assembly. Most of these savings (EUR 12,037) come from debt waives with four cases representing $49.7 \%$ of the total savings obtained through this action (one of these cases sums EUR 4200 while the rest represents between EUR 2000 and EUR 1000 each). Around EUR 2500 in savings were achieved by informing and empowering CAA participants to apply available support mechanisms, primarily the social bonus. Advice for the reduction in the contracted power and change from a flat rate to a ToU tariff (48 cases) is estimated to result in economic savings of about EUR 1000. The rest of the savings come from supply regularization (51 cases, from which 36 were led by women) or claims for maintenance refunds and not because of active energy saving suggestions.

\section{Discussion}

Activities carried out by APE in Barcelona, and in particular, CAAs and the monitoring campaign performed in the framework of the EmpowerMed project were analyzed in the present work. They allow a detailed characterization of EP-affected persons that participated in these activities and provide evidence of CAAs and electricity consumption and indoor environmental comfort monitoring as support tools to tackle energy poverty.

Data collected through the CAA survey $(n=74)$ indicate that people attending CAAs constitute a population severely affected by EP: they show higher levels of housing insecurity (49\% rented and 35\% irregularly occupied dwellings), precarious material living conditions $(75 \%$ of the people reports inadequate housing conditions at home, e.g., mold, humidity, leaky windows, etc.), low incomes (average monthly income around 500 EUR/equivalent person), high levels of thermal discomfort (93\% are unable to keep their home adequately warm in winter) and of arrears on utility bills (64\%). Around $60 \%$ of participants are women, $43 \%$ have children at home, and persons with disabilities are present in $24 \%$ of the households. Comparing those characteristics with the sample data from non-EP-affected persons, the insecurity of their living conditions becomes more evident: the average equivalised income of an EP household is 3 times lower than for a non-EP household. Consequently, EP-affected persons have the need to reduce their 
expenditure in a variety of basic services and essential goods to pay for utility bills, very much unlike non-EP households. Previous work by Yoon and Saurí [58] also based on collected data from APE's participants during 2015-2016 shows similar patterns about socioeconomic characteristics of the EP participants. In this earlier study, most participants in APE CAAs were persons at risk of social exclusion. There was a high concentration of female participants (61\%) and single-parent households, which on average have larger families (3.1 members) compared to the Catalan average of 2.1 members per household. Furthermore, 64\% lived on monthly household incomes of less than EUR 750, and 36\% lived on less than EUR 450. Single-parent (mother) families were especially vulnerable, as $21 \%$ of them did not have any income. Similar patterns were observed in other Spanish cities like Madrid, where Sanchez-Guevara et al. [17] observed that the income of singleperson households with women over 65 tends to be significantly lower than the income in single-person households of men over 65. Additionally, women tend to be responsible for caregiving tasks and have higher rates of unemployment or part-time jobs, meaning they spend more hours at home, and are therefore exposed for longer times to inadequate temperatures when the household experiences EP conditions.

Figures about indebtedness with utility providers, supply disconnections and irregular connections to the supply presented in Table 4 are confirmed by a previous semiquantitative assessment of domestic energy-related problems faced by CAA participants. Canals et al. [59] report significant difficulties related to the security and stability of basic utility services supply ( $45 \%$ of survey respondents). In this earlier work, a many as $25 \%$ of the 286 households mentioned in APE's 78 "energy poverty chronicles" (i.e., short summaries of bimonthly CAA held by the APE in Barcelona) collected between November 2014 and March 2018 referred to utility-enforced electricity supply disconnections (versus 3\% of natural gas and $13 \%$ of water). They also reported high rates of arrears or failed payments ( $23 \%$ for electricity, $8 \%$ for natural gas and $12 \%$ for water). These percentages, as well the figures reported in this paper, are well above incidence rates reported for these EP issues in Barcelona, Catalonia and Spain, which on average affect only a small fraction (below 5\%) of the overall population [60].

The monitoring campaign carried out with the voluntary participation of 27 households has also allowed comparing the EP and non-EP-affected households in terms of thermal comfort, indoor air quality, electricity consumption and costs. These results clearly illustrate the benefits of taking part in APE's CAAs. The analysis of the monitored thermal comfort data for the 27 households suggests minor differences between EP and non-EP households. However, if wintertime thermal comfort perceptions are compared, a significant difference between groups emerge, as EP-affected persons report worse thermal conditions at home (an average of 3.6/10 thermal comfort perception, compared to 5.7/10 for non-EP persons; $93 \%$ of EP households cannot keep home adequately warm in winter, compared to $46 \%$ of non-EP households). The discrepancy between monitored temperature data and thermal comfort perception could be explained by considering that thermal comfort depends both on physical parameters (environmental and architectural characteristics of the building) and the sociocultural characteristics of the person and household. In that case, the physical parameters are reasonably similar between groups $(74 \%$ with low energy efficiency in buildings and $75 \%$ inadequate housing conditions for both) and thanks to the social bonus, EP-affected households are able to maintain the temperature of the household in at least Category III most of the time, similarly to non-EP households. Nevertheless, the main difference appears to be related to the group's socioeconomic situation as EP-affected persons report high levels of dissatisfaction in relation to thermal comfort as well as very low incomes, arrears on utility bills, deprivation of basic services and essential goods, health conditions. This dissatisfaction could be related to a strong association between EP and the emotional burden of living in EP. Some examples of mechanisms and pathways through which EP affects emotional wellbeing may be constant worries about energy bills or about falling into debt and the absence of any solution or sense of control over the problem [15]. Additionally, another aspect that could influence the thermal comfort perception 
is that $86 \%$ of EP-affected persons spend most of the day at home, in comparison with just $46 \%$ of non-EP households. On the contrary, the perception of thermal comfort in summer is quite similar between groups $(6 / 10$ on average for both) but then the monitored periods do not cover this season to make the comparison using sensor data.

Regarding indoor air quality, EP-affected households present worse levels despite the adequate natural ventilation habits of the occupants. Two main reasons could cause that situation: $86 \%$ of the EP-affected households are occupied almost all day, and $36 \%$ use butane heaters. Further data would be needed to evaluate additional air quality indicators in those households where butane heaters are used, as $\mathrm{CO}_{2}$ concentration is a tracer of human occupancy and of indoor open fire combustion as well. In these cases it would be necessary to track the presence of other pollutants that can derive from the combustion of butane gas, such as CO or PM.

A limitation of the indoor environmental comfort campaign is that all households are not monitored during the same period of time, complicating direct comparison. To partially solve this limitation, average outdoor temperatures were taken into account for the analysis, in order to relate monitored thermal comfort with weather conditions. Furthermore, there is only one household monitored in summer weather conditions, and the comparison between comfort perception and monitored data in the summertime cannot be made.

The analysis of the electricity consumption based on data retrieved from the smart meters of 19 households that participated in the monitoring campaign also demonstrates small differences across EP and non-EP households. The EP-affected report consumption levels $8 \%$ lower than non-EP, when comparing the electricity consumption per equivalent person. Such a small difference between the two groups could be due to the social bonus discount on electricity bills, which $70 \%$ of EP households had at the time of the monitoring campaign and likely helps them maintain adequate electricity consumption levels. Focusing on the seasonal variation, the main difference is observed in the winter period, where the electricity consumption of EP-affected households is lower than non-affected; however, the trend is opposite in summer, manifesting smaller variations between groups. The wintertime behavior could respond to EP-affected households' need to reduce their basic services expenditures for economic reasons, despite the access to social bonuses. As a comparison, the study of Gouveia et al. [12] in Portugal observed how similar energy subsidies (social tariff) were provided for EP households minimizing the high-energy costs, even if as a support mechanism it did not provide a sustainable long-term solution addressing the root causes of the thermal performance gap.

While differences in electricity consumption are relatively small, the variation on estimated annual electricity costs is substantially higher: non-EP households pay around $18 \%$ more than EP households, and $46 \%$ if the social bonus is considered. Electricity is more expensive for non-EP households because of a combination of effects: only EPaffected households have regulated tariff contracts, with cheaper prices; the contracted power (which represents around $50-60 \%$ of the electricity bill) is lower in EP households; and, thanks to the social bonus, the EP group can reduce the electricity expenses by an average of $20 \%$. Consequently, the electricity monitoring tool reported potential savings nearly 2 times higher (around 100 EUR/year) for non-affected households than for EPaffected households, meaning that EP-affected households participating in APE's CAAs are definitely aware of the costs of electricity and apply most of the available strategies. The most common suggestion to reduce the electricity bill provided by the electricity monitoring tool is to change from a free market to a regulated tariff contract under a ToU tariff. A similar approach to the electricity monitoring tool was used by Antepara et al. [20] for an initiative addressing energy poverty in two municipalities in the Basque Country. The project also evaluated the electricity contracts of vulnerable customers, suggesting changes to minimize their costs based on their current contracting conditions and consumption profile, which is registered by the users' smart-meter and accessed through the distribution system operator's (DSO) website. The potential savings estimated by Antepara et al. are between $10 \%$ and $40 \%$ of the user's annual electricity expenses. 
For the electricity monitoring campaign, two main limitations are identified. The first is that the sample of households was reduced from 27 to 19 due to several situations (lack of sufficient data caused by smart-meter malfunction, shorter contract validity period or irregular electricity supply access conditions) resulting in a smaller sample. Second, the annual consumption data collected for each household do not always cover the same period of time, meaning that weather conditions or the COVID-19 pandemic may have a different impact on the households' electricity consumption patterns depending on the accessed period.

Finally, these data show that CAAs do empower vulnerable customers, allowing them to reduce their electricity costs by selecting the most suitable tariffs and enabling them access to the social bonus. This effect is observed when comparing EP-affected households that have recently joined the CAA against those that have participated for several months. Data are from the CAA monitoring tool. Debt write-off was possible due to the agreement between the Catalan Government and dominant water and electricity companies in Catalonia, which were achieved in 2018 and 2021, respectively, in response to the advocacy campaign carried out by APE since 2015.

\section{Conclusions}

The present work characterizes the EP population that attends to APE's CAAs, a collaborative empowering engagement tool based on a horizontal participatory methodology in which people affected by EP receive advice and support from an "assembly of peers". Furthermore, the paper describes and analyzes the results of EmpowerMed interventions offered to CAA participants, consisting of an electricity and indoor environmental comfort monitoring campaign to optimize electricity supply contracts and provide recommendations for comfort improvement. Finally, a comparison of a small sample of EP households with non-EP-affected households is provided.

CAA participants represent a population severely affected by EP that experiences and report high levels of housing insecurity, precarious material living conditions, low incomes, high levels of thermal discomfort and arrears on utility bills. Around $60 \%$ of participants are women, $43 \%$ have children at home, and persons with disabilities are present in $24 \%$ of the households. These characteristics are found in previous studies of APE, which confirm that CAAs are a useful and necessary space to give support to the most vulnerable groups of the population.

The environmental comfort analysis demonstrates that in general terms, EP-affected households report worst thermal comfort and indoor air quality conditions than non-EP households. However, some differences are highlighted. The thermal comfort indexes, obtained from the monitored data in winter do not reveal significant differences in indoor temperatures measured through sensors between groups; nevertheless, reported thermal comfort perception in the wintertime is considerably worse than in EP households than non-EP. This variation between monitored data and thermal comfort perception could be explained by the subjectivity behind thermal comfort and the strong association between $\mathrm{EP}$ and emotional wellbeing. In terms of indoor air quality, the worst conditions are found in EP households with butane heaters. Further monitoring campaigns would be needed to assess thermal comfort conditions in summer and monitoring additional pollutants to evaluate the impact of use butane heaters.

In terms of electricity consumption, data retrieved from smart meters indicate a small difference between EP and non-EP households, with EP-affected households reporting just $8 \%$ less electricity usage per equivalent person. The difference is primarily explained by the social bonus discount on electricity bills and their empowerment through the participation of APE's CAAs, which allows EP households to keep adequate electricity consumption levels. The analysis of electricity expenses also revealed that EP-affected households have lower electricity costs compared to non-EP households, demonstrating that EP-affected households participating in APE's CAAs are definitely aware of the costs of electricity and capable to be in control and optimize their electricity supply contracts. In addition to 
the social bonus, the other two mechanisms through which EP-affected households have lower electricity bills than non-EP are having a regulated tariff contract and having a lower contracted power in their supply contract.

In conclusion, the data collected by the EmpowerMed project in Barcelona demonstrate that CAAs as a community-based engagement methodology devised and put in practice by APE serve to empower and provide material support to persons severely affected by EP. They do so through the provision of information about their rights, of administrative and legal support, of specific recommendations about tariffs and utility contracts, by the accompaniment' EP-affected households by activists and people dealing with similar EP issues, and also thanks to APE's intense advocacy activity targeting utility companies and public authorities. Recently, APE has also identified the necessity to accompany EP-affected persons from a health point of view. To this aim, the mutual support workshops were launched with the objective of covering that emotional wellbeing dimension of EP. All in all, CAAs stand out as a powerful communitarian alternative for tackling energy poverty beyond the provision of individualized forms of support to vulnerable customers.

Author Contributions: Conceptualization, J.O., M.J.M., S.T.-H., I.G.P., M.G.B. and L.C.C.; methodology, J.O., M.J.M., S.T.-H. and L.C.C.; software, M.J.M. and L.C.C.; validation, M.J.M. and L.C.C.; formal analysis, J.O., M.J.M., A.A.-S., S.T.-H. and L.C.C.; investigation, J.O., M.J.M., A.A.-S., S.T.-H. and L.C.C.; writing-Original draft preparation, J.O., M.J.M., A.A.-S., S.T.-H. and L.C.C.; writingReview and editing, J.O., M.J.M., S.T.-H. and L.C.C.; visualization, J.O. and M.J.M.; supervision, J.O.; project administration, J.O. All authors have read and agreed to the published version of the manuscript.

Funding: The research conducted in this paper is part of the EmpowerMed project that has received funding from the European Union's Horizon 2020 research and innovation programme under grant agreement No 847052. All researchers from IREC have been partially supported by the Generalitat de Catalunya (2017 SGR 1219).

Institutional Review Board Statement: Ethical review and approval were waived for this study due to no action on humans was done in the study. The study only collects information from subjects and treats it in anonymized way.

Informed Consent Statement: Informed consent was obtained from all subjects involved in the study.

Data Availability Statement: The data are not publicly available due to confidential reasons.

Acknowledgments: The researchers of this project thank Aliança contra la Pobresa Energètica-APE for their collaboration, as well as the volunteers that participate in the monitoring campaign.

Conflicts of Interest: The authors declare no conflict of interest. The funders had no role in the design of the study; in the collection, analyses, or interpretation of data; in the writing of the manuscript, or in the decision to publish the results.

\section{Appendix A}

Table A1. Prices per kilowatt-hour during peak, valley and supervalley periods, and per kilowatt of contracted power used for the calculation of electricity costs in the liberalized market (June 2020).

\begin{tabular}{cccccc}
\hline Company & Tariff Name & $\begin{array}{c}\text { Peak } \\
\text { [EUR/kWh] }\end{array}$ & $\begin{array}{c}\text { Valley } \\
\text { [EUR/kWh] }\end{array}$ & $\begin{array}{c}\text { Super-Valley } \\
\text { [EUR/kWh] }\end{array}$ & $\begin{array}{c}\text { Contracted Power } \\
\text { [EUR/kW] }\end{array}$ \\
\hline Bassols & Hogar 24 Horas & 0.132690 & - & - & 0.123069 \\
\hline EDP & Luz Máximo Ahorro & 0.127947 & - & - & 0.116302 \\
\hline Electracomercial Centellas & Tarifa 2 & 0.130568 & - & - & 0.106023 \\
\hline Endesa & One Luz & 0.119893 & - & - & 0.114323 \\
\hline Estabanell Energia & Plan Premium & 0.139755 & - & - & 0.121649 \\
\hline
\end{tabular}


Table A1. Cont.

\begin{tabular}{|c|c|c|c|c|c|}
\hline Company & Tariff Name & $\begin{array}{c}\text { Peak } \\
\text { [EUR/kWh] }\end{array}$ & $\begin{array}{c}\text { Valley } \\
\text { [EUR/kWh] }\end{array}$ & $\begin{array}{l}\text { Super-Valley } \\
\text { [EUR/kWh] }\end{array}$ & $\begin{array}{c}\text { Contracted Power } \\
\text { [EUR/kW] }\end{array}$ \\
\hline Factor Energía & Tarifa Fija & 0.139406 & - & - & 0.105676 \\
\hline Iberdrola & Plan Estable & 0.114656 & - & - & 0.125000 \\
\hline Naturgy & EcoEasy Luz & 0.106000 & - & - & 0.125000 \\
\hline Nexus Energía & Luz Clásica & 0.127000 & - & - & 0.104200 \\
\hline PEUSA & $24 \mathrm{~h}$ & 0.152400 & - & - & 0.132500 \\
\hline Som Energia & $2.0 \mathrm{~A} \mathrm{SOM}$ & 0.139000 & - & - & 0.103944 \\
\hline Bassols & Hogar Noche & 0.157284 & 0.07851 & - & 0.123069 \\
\hline EDP & Fórmula Luz & 0.154797 & 0.08631 & - & 0.116302 \\
\hline Electracomercial Centellas & $2.0 \mathrm{DH}$ & 0.150366 & 0.072869 & - & 0.106023 \\
\hline Endesa & One Luz Nocturna & 0.158614 & 0.07942 & - & 0.114323 \\
\hline Estabanell Energia & Plan Luz Día y Noche & 0.164646 & 0.08811 & - & 0.121649 \\
\hline Iberdrola & Plan Noche & 0.134579 & 0.067519 & - & 0.125000 \\
\hline Nexus Energía & Luz Clásica 2H & 0.144000 & 0.07600 & - & 0.104200 \\
\hline PEUSA & Nocturna & 0.184800 & 0.08250 & - & 0.132500 \\
\hline Som Energia & 2.0 DHA SOM & 0.161000 & 0.08200 & - & 0.103944 \\
\hline Bassols & Hogar Ahorro & 0.155854 & 0.088473 & 0.070335 & 0.123069 \\
\hline Bassols & Hogar Movilidad & 0.155854 & 0.088473 & 0.068304 & 0.123069 \\
\hline Electracomercial Centellas & 2.0 DHS & 0.150802 & 0.075006 & 0.058982 & 0.106023 \\
\hline Endesa & Tempo Verde Supervalle & 0.154701 & 0.088909 & 0.076377 & 0.126181 \\
\hline Estabanell Energia & Plan Vehículo Eléctrico & 0.157067 & 0.091912 & 0.075394 & 0.121649 \\
\hline PEUSA & Mobilitat & 0.198700 & 0.116800 & 0.085500 & 0.132500 \\
\hline Som Energia & 2.0 DHS SOM & 0.160000 & 0.091000 & 0.073000 & 0.103944 \\
\hline
\end{tabular}

\section{References}

1. Bouzarovski, S.; Petrova, S. A global perspective on domestic energy deprivation: Overcoming the energy poverty-fuel poverty binary. Energy Res. Soc. Sci. 2015, 10, 31-40. [CrossRef]

2. Bouzarovski, S.; Thomson, H. Transforming Energy Poverty Policies in the European Union: Second Annual Report of the European Union Energy Poverty Observatory; EU Energy Poverty Observatory: Manchester, UK, 2019.

3. Recalde, M.; Peralta, A.; Oliveras, L.; Tirado-Herrero, S.; Borrell, C.; Palència, L.; Gotsens, M.; Artazcoz, L.; Marí-Dell'Olmo, M. Structural energy poverty vulnerability and excess winter mortality in the European Union: Exploring the association between structural determinants and health. Energy Policy 2019, 133, 110869. [CrossRef]

4. Bouzarovski, S.; Tirado-Herrero, S. The energy divide: Integrating energy transitions, regional inequalities and poverty trends in the European Union. Eur. Urban. Reg. Stud. 2015, 24, 69-86. [CrossRef] [PubMed]

5. Boardman, B. Fuel Poverty: From Cold Homes to Affordable Warmth; Pinter Pub Limited: London, UK, 1991.

6. Kyprianou, I.; Serghides, D.K.; Varo, A.; Gouveia, J.P.; Kopeva, D.; Murauskaite, L. Energy poverty policies and measures in 5 EU countries: A comparative study. Energy Build. 2019, 196, 46-60. [CrossRef]

7. Bouzarovski, S.; Thomson, H.; Cornelis, M. Confronting energy poverty in Europe: A research and policy agenda. Energies 2021, 14, 858. [CrossRef]

8. Longo, D.; Olivieri, G.; Roversi, R.; Turci, G.; Turillazzi, B. Energy poverty and protection of vulnerable consumers. Overview of the EU funding programs FP7 and H2020 and future trends in horizon Europe. Energies 2020, 13, 1030. [CrossRef]

9. Meyer, S.; Laurence, H.; Bart, D.; Lucie, M.; Kevin, M. Capturing the multifaceted nature of energy poverty: Lessons from Belgium. Energy Res. Soc. Sci. 2018, 40, 273-283. [CrossRef]

10. Sánchez-Guevara Sánchez, C.; Sanz Fernández, A.; Núñez Peiró, M.; Gómez Muñoz, G. Energy poverty in Madrid: Data exploitation at the city and district level. Energy Policy 2020, 144, 111653. [CrossRef]

11. Karpinska, L.; Śmiech, S. Breaking the cycle of energy poverty. Will Poland make it? Energy Econ. 2021, 94, 105063. [CrossRef]

12. Gouveia, J.P.; Seixas, J.; Long, G. Mining households' energy data to disclose fuel poverty: Lessons for Southern Europe. J. Clean. Prod. 2018, 178, 534-550. [CrossRef] 
13. Fabbri, K.; Gaspari, J. Mapping the energy poverty: A case study based on the energy performance certificates in the city of Bologna. Energy Build. 2021, 234, 110718. [CrossRef]

14. Mohan, G. Young, poor, and sick: The public health threat of energy poverty for children in Ireland. Energy Res. Soc. Sci. 2021, 71, 101822. [CrossRef]

15. Oliveras, L.; Artazcoz, L.; Borrell, C.; Palència, L.; López, M.J.; Gotsens, M.; Peralta, A.; Marí-Dell'Olmo, M. The association of energy poverty with health, health care utilisation and medication use in southern Europe. SSM Popul. Health 2020, $12,100665$. [CrossRef] [PubMed]

16. Middlemiss, L.; Ambrosio-Albalá, P.; Emmel, N.; Gillard, R.; Gilbertson, J.; Hargreaves, T.; Mullen, C.; Ryan, T.; Snell, C.; Tod, A. Energy poverty and social relations: A capabilities approach. Energy Res. Soc. Sci. 2019, 55, 227-235. [CrossRef]

17. Sánchez-Guevara Sánchez, C.; Sanz Fernández, A.; Núñez Peiró, M.; Gómez Muñoz, G. Feminisation of energy poverty in the city of Madrid. Energy Build. 2020, 223, 110157. [CrossRef]

18. Papada, L.; Kaliampakos, D. Measuring energy poverty in Greece. Energy Policy 2016, 94, 157-165. [CrossRef]

19. Castaño-Rosa, R.; Solís-Guzmán, J.; Rubio-Bellido, C.; Marrero, M. Towards a multiple-indicator approach to energy poverty in the European Union: A review. Energy Build. 2019, 193, 36-48. [CrossRef]

20. Antepara, I.; Claeyé, F.; Lopez, A.; Benoît, R. Fighting against fuel poverty by collaborating with social services through energy advice: An innovative case from Spain. Gizarte Ekon. Euskal Aldizka. Rev. Vasca Econ. Soc. 2020, 17, 71-96. [CrossRef]

21. González Pijuan, I.; Tirado-Herrero, S. Àrea Metropolitana de BARCELONA. Anàlisi de cas Pilot. Available online: https: //www.empowermed.eu/wp-content/uploads/2020/11/Barcelona-Pilot-Site.pdf (accessed on 16 August 2021).

22. González Pijuan, I. Desigualdad de género y pobreza energética. Un factor de riesgo olvidado. ESFeres Estudios. 2017, 17. Available online: https:/ / esf-cat.org/wp-content/uploads/2017/09/ESFeres17-PobrezaEnergeticaiDesigualdadGenero.pdf (accessed on 16 August 2021).

23. Petrova, S.; Simcock, N. Gender and energy: Domestic inequities reconsidered. Soc. Cult. Geogr. 2021, 22, 849-867. [CrossRef]

24. Bradshaw, S.; Chant, S.; Linneker, B. Gender and poverty: What we know, don't know, and need to know for Agenda 2030. Gender Place Cult. 2017, 24, 1667-1688. [CrossRef]

25. Parsons, K. Human Thermal Environments: The Effects of Hot, Moderate, and Cold Environments on Human Health, Comfort and Performance, 2nd ed.; CRC Press: Boca Raton, FL, USA, 2002.

26. Braubach, M.; Jacobs, D.E.; Ormandy, D. Environmental Burden of Disease Associated with Inadequate Housing: A Method Guide to the Quantification of Health Effects of Selected Housing Risks in the WHO European Region; World Health Organization: Geneva, Switzerland, 2011; ISBN 978-92-890-0239-4.

27. Bonnefoy, X. Inadequate housing and health: An overview. Int. J. Environ. Pollut. 2007, 30, 411-429. [CrossRef]

28. Liddell, C.; Morris, C. Fuel poverty and human health: A review of recent evidence. Energy Policy 2010, 38, 2987-2997. [CrossRef]

29. Anderson, W.; White, V.; Finney, A. Coping with low incomes and cold homes. Energy Policy 2012, 49, 40-52. [CrossRef]

30. Tod, A.M.; Nelson, P.; Cronin de Chavez, A.; Homer, C.; Powell-Hoyland, V.; Stocks, A. Understanding influences and decisions of households with children with asthma regarding temperature and humidity in the home in winter: A qualitative study. BMJ Open 2016, 6, e009636. [CrossRef] [PubMed]

31. Oliveras, L.; Peralta, A.; Palència, L.; Gotsens, M.; López, M.J.; Artazcoz, L.; Borrell, C.; Marí-Dell'Olmo, M. Energy poverty and health: Trends in the European Union before and during the economic crisis, 2007-2016. Health Place 2021, 67, 102294. [CrossRef] [PubMed]

32. Mohan, G. The impact of household energy poverty on the mental health of parents of young children. J. Public Health 2021. [CrossRef] [PubMed]

33. Marmot Review Team. The Health Impacts of Living in a Cold Home and Fuel Poverty; Friends of the Earth \& the Marmot Review Team: London, UK, 2011.

34. Liddell, C.; Guiney, C. Living in a cold and damp home: Frameworks for understanding impacts on mental well-being. Public Health 2015, 129, 191-199. [CrossRef]

35. Gómez-Navarro, T.; Pastor, M.; Pellicer-Sifres, V.; Lillo-Rodrigo, P.; Alfonso-Solar, D.; Pérez-Navarro, A. Fuel poverty map of Valencia (Spain): Results of a direct survey to citizens and recommendations for policy making. Energy Policy 2021, $151,112162$. [CrossRef]

36. Creutzfeldt, N.; Gill, C.; McPherson, R.; Cornelis, M. The social and local dimensions of governance of energy poverty: Adaptive responses to state remoteness. J. Consum. Policy 2020, 43, 635-658. [CrossRef]

37. Ley 24/2013, de 26 de Diciembre, del Sector Eléctrico. 2013. Available online: https://www.boe.es/buscar/act.php?id=BOE-A2013-13645 (accessed on 16 August 2021).

38. Haar, L. Inequality and renewable electricity support in the European Union. In Inequality and Energy; Elsevier: Amsterdam, The Netherlands, 2020; pp. 189-220.

39. Pinto-Bello, A. The smartEn Map. Network Tariffs and Taxes-2019; smartEn (Smart Energy Europe): Barcelona, Spain, 2020; Available online: https://smarten.eu/wp-content/uploads/2019/12/the_smarten_map_2019.pdf (accessed on 12 August 2021).

40. Eurostat. Electricity Prices for Household Consumers-Bi Annual Data (from 2007 Onwards). Available online: http:/ /appsso. eurostat.ec.europa.eu/nui/show.do?dataset=nrg_pc_204 (accessed on 13 August 2021). 
41. Comisión Nacional de los Mercados y la Competencia-España. Circular 3/2020, de 2 de julio, de la Comisión Nacional de los Mercados y la Competencia, por la que Se Establece la Metodología para el Cálculo de los Peajes de Transporte y Distribución de Electricidad; Boletín Oficial del Estado: Madrid, Spain, 2020; Volume 24, pp. 57158-57184.

42. Comisión Nacional de los Mercados y la Competencia-España. Circular 3/2014, de 2 de julio, de la Comisión Nacional de los Mercados y la Competencia, por la que Se Establece la Metodología para el Cálculo de los Peajes de Transporte y Distribución de Electricidad; Boletín Oficial del Estado: Madrid, Spain, 2014.

43. Ministerio de Energía Turismo y Agenda Digital-España. Real Decreto 897/2017, de 6 de Octubre, por el que Se Regula la Figura del Consumidor Vulnerable, el Bono Social y Otras Medidas de Protección para los Consumidores Domésticos de Energía Eléctrica; Agencia Estatal Boletín Oficial del Estado: Madrid, Spain, 2017; Volume 242, p. 47995.

44. Instituto Nacional de Estadística-España Censos de Población y Vivienda 2011. Available online: https://www.ine.es/ dyngs /INEbase/es /operacion.htm?c=Estadistica_C\&cid=1254736176992\&menu=ultiDatos\&idp=1254735576757 (accessed on 14 August 2021).

45. Cuchí, A.; Sweatman, P. A National Perspective on Spain's Buinding Sector. A Roadmap for A New Housing Sector; Green Building Council Spain: Madrid, Spain; Fundacion CONAMA: Madrid, Spain, 2011.

46. EU Energy Poverty Observatory EU Energy Poverty Obervatory-Indicators \& Data. Available online: https://www. energypoverty.eu/indicators-data (accessed on 15 August 2021).

47. Ley 24/2015, de 29 de julio, de Medidas Urgentes para Afrontar la Emergencia en el Ámbito de la Vivienda y la Pobreza Energética; Boletín Oficial del Estado: Madrid, Spain, 2015. Available online: https://www.boe.es/eli/es-ct/1/2015/07/29/24 (accessed on 14 August 2021).

48. EmpowerMed Collective Advisory Assembly Monitoring Tool. Available online: https://www.empowermed.eu/wp-content/ uploads/2021/07/Collective-assembly_calculation-tool.xlsx (accessed on 13 August 2021).

49. EmpowerMed Detailed Monitoring Survey. Available online: https://www.empowermed.eu/wp-content/uploads/2021/07/ Collective-assembly_initial-and-intermediate-data-collection-questionnaire.pdf (accessed on 12 August 2021).

50. UNE EN 16798-1:2019. Energy Performance of Building_Ventilation for Buildings_Part 1: Indoor Environmental Input Parameters for Design and Assessment of Energy Performance of Buildings Addressing Indoor Air Quality, Thermal Environment, Lighting and Acous; UNE Normalización Española: Madrid, Spain, 2019; Available online: https:/ / standards.iteh.ai/catalog/standards/cen/b4f687 55-2204-4796-854a-56643dfcfe89/en-16798-1-2019 (accessed on 20 August 2021).

51. ASHRAE 55. ANSI/ASHRAE Standard 55-2017, Thermal Environmental Conditions for Human Occupancy; American Society of Heating Refrigerating and Air-Conditioning Engineers Inc.: Atlanta, GA, USA, 2017.

52. Edistribución. Zona Privada Edistribucion. Available online: https://zonaprivada.edistribucion.com/areaprivada/s (accessed on 7 July 2021).

53. Red Eléctrica de España REDdata API. Available online: https:/ /www.ree.es/es/apidatos (accessed on 22 August 2021).

54. Gobierno de España. Ministerio de Industria Energía y Turismo Real Decreto 216/2014, de 28 de Marzo, por el que Se Establece la Metodología de Cálculo de los Precios Voluntarios para el Pequeño Consumidor de Energía Eléctrica y su Régimen Jurídico de Contratación; 2014; Volume 77, pp. 27397-27428. Available online: https:/ / www.boe.es/buscar/doc.php?id=BOE-A-2014-3376 (accessed on 21 August 2021).

55. Orden IET/107/2014, de 31 de Enero, por la Que se Revisan los Peajes de Acceso de Energía Eléctrica Para 2014. Boletín Oficial del Estado: Madrid, Spain, 2014; p. 23. Available online: https://www.boe.es/eli/es/o/2014/01/31/iet107 (accessed on 22 August 2021).

56. Ministerio Para la Transición Ecológica y el Reto Demográfico-España. Conceptos por los que Pago en la Factura de Electricidad. Available online: Controlastuenergia.gob.es/factura-electrica/factura/paginas/conceptos-factura.aspx (accessed on 22 August 2021).

57. Comisión Nacional de los Mercados y la Competencia-España. Solo Uno de Cada Cuatro Hogares Españoles Conoce la Diferencia entre Mercado Libre y Regulado del Sector Eléctrico. Available online: https://www.cnmc.es/prensa/cnmc-panelenergía-20201204 (accessed on 22 August 2021).

58. Yoon, H.; Sauri, D.; Domene, E. The water-energy vulnerability in the Barcelona metropolitan area. Energy Build. 2019, 199, 176-189. [CrossRef]

59. Canals Casals, L.; Tirado-Herrero, S.; Barbero, M.; Corchero, C. Smart meters tackling energy poverty mitigation: Uses, risks and approaches. In Proceedings of the 2020 IEEE Electric Power and Energy Conference (EPEC), Edmonton, AB, Canada, 9 November 2020; pp. 1-6.

60. Tirado-Herrero, S. Indicadores Municipales de Pobreza Energética en la Ciudad de Barcelona; RMIT Europe: Barcelona, Spain, 2018. 